\title{
Mechanistic and Kinetic Study on Self-/Cross- Condensation of PCTA/DT Formation Mechanisms from Three Types of Radicals of 2,4-Dichlorothiophenol
}

\author{
Hetong Wang ${ }^{1}$, Chenpeng Zuo ${ }^{1}$, Siyuan Zheng ${ }^{1}$, Yanhui Sun ${ }^{2}$, Fei Xu ${ }^{1,3, *}$ and Qingzhu Zhang ${ }^{1}$ \\ 1 Environment Research Institute, Shandong University, Qingdao 266237, China; Kishi_Wang@163.com (H.W.); \\ zuochenpeng@126.com (C.Z.); zhengsiyuan1991@126.com (S.Z.); zqz@sdu.edu.cn (Q.Z.) \\ 2 College of Environment and Safety Engineering, Qingdao University of Science \& Technology, \\ Qingdao 266042, China; sunyh0532@126.com \\ 3 Shenzhen Research Institute, Shandong University, Shenzhen 518057, China \\ * Correspondence: xufei@sdu.edu.cn; Tel.: +86-532-5863-1992
}

Received: 23 April 2019; Accepted: 26 May 2019; Published: 28 May 2019

check for updates

\begin{abstract}
Chlorothiophenols (CTPs) are known to be key and direct precursors of polychlorinated thianthrene/dibenzothiophenes (PCTA/DTs). Self/cross-coupling of the chlorothiophenoxy radicals (CTPRs), sulfydryl-substituted phenyl radicals and thiophenoxyl diradicals evolving from CTPs are initial and important steps for PCTA/DT formation. In this study, quantum chemical calculations were carried out to investigate the homogenous gas-phase formation of PCTA/DTs from self/cross-coupling of 2,4-dichlorothiophenoxy radical (R1), 2-sulfydryl-3,5-dichlorophenyl radical (R2) and 3,5-dichlorothiophenoxyl diradical (DR) at the MPWB1K/6-311+G(3df,2p)//MPWB1K/6-31+G(d,p) level. The rate constants of crucial elementary steps were deduced over 600-1200 K, using canonical variational transition state theory with a small curvature tunneling contribution. For the formation of

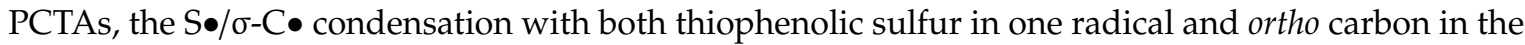
other radical bonded to single electron is the most efficient sulfur-carbon coupling mode, and the ranking of the PCTA formation potential is DR + DR > R2 + DR $>\mathrm{R} 1+\mathrm{DR}>\mathrm{R} 1+\mathrm{R} 2>\mathrm{R} 1+\mathrm{R} 1$. For the formation of PCDTs, the $\sigma-\mathrm{C} \bullet / \sigma-\mathrm{C} \bullet$ coupling with both ortho carbon in the two radicals bonded to single electron is the energetically favored carbon-carbon coupling mode, and the ranking of the PCDT formation potential is: $\mathrm{R} 2+\mathrm{DR}>\mathrm{R} 2+\mathrm{R} 2>\mathrm{R} 1+\mathrm{DR}>\mathrm{R} 1+\mathrm{R} 2>\mathrm{R} 1+\mathrm{R} 1$. The PCTA/DTs could be produced from R1, R2 and DR much more readily than PCDD/DFs from corresponding oxygen substituted radicals.
\end{abstract}

Keywords: 2,4-dichlorothiophenoxy radical; 2-sulfydryl-3,5-dichlorophenyl radical; 3,5-dichlorothiophenoxyl diradical; PCTA/DTs; formation mechanism; rate constants

\section{Introduction}

Polychlorinated thianthrene/dibenzothiophenes (PCTA/DTs) are two groups of sulfur-substituted structural analogues of the polychlorinated dibenzo-p-dioxin/dibenzofurans (PCDD/DFs), which are persistent, lipophilic and considered to be dioxin-like compounds [1]. In general, PCTA/DTs exhibit less toxicity than PCDD/DFs with the toxicity equivalent factor (TEF) of 2,3,7,8-TeCTA and 2,3,7,8-TeCDT as 0.01 and 0.001 , respectively [2]. Kopponen et al. found that the potency of 2,3,7,8-tetrachlorothianthrene (TeCTA) and 2,3,7,8-tetrachlorodibenzothiophene (TeCDT) to induce aryl hydrocarbon hydroxylase $(\mathrm{AHH})$ is reported to be approximately $1 / 400$ that of 2,3,7,8-TeCDD [3]. Owning to the difference of chlorine substitution positions and numbers, PCTA/DTs are identified as having 75 congeners 
of PCTAs and 135 congeners of PCDTs. Among them, 2,4,6,8-TeCDT is the most widely detected PCTA/DTs [4-12]. For example, Buser et al. reported that 2,4,6,8-TCDT constitutes approximately 95\% of the total TCDT in the Passaic River [6]. PCTA/DTs have similar and even much higher concentration in some regions and bioaccumulation potential than PCDD/DFs $[4,13]$, which have been detected in the different environmental samples, including soil and sediment [11,14], pulp bleaching [1], incineration of municipal waste [15,16], wastes from petroleum refineries [17] and petroleum spills [18]. For example, Rappe et al. reported the presence of PCDTs in emissions from iron and steel sintering plants and foundries at approximately the same concentrations as PCDFs [8]. Cai et al. found that blue crabs included more 2,4,6,8-TeCDT than 2,3,7,8-TeCDT in their muscle and hepato-pancreatic tissues [19]. Pruell et al. observed that the mean concentrations of 2,4,6,8-TeCDT (3680 ng/kg) in Passaic River sediments were 5-10 times higher than that of 2,3,7,8-TeCDD $(656 \mathrm{ng} / \mathrm{kg})$ and 2,3,7,8-TeCDF (334 ng/kg) [11]. Thus, considering the serious environmental pollution and wide concern by scientific researchers of these toxic substances, it is significant to clarify the formation mechanism of PCTA/DTs under combustion and thermal processes to hinder their harm to humans and the environment.

PCTA/DTs were never intentionally synthesized for commercial purposes, but are formed as byproducts from a variety of combustion and thermal processes such as municipal and hazardous waste incinerators as well as industrial incinerators [6,7]. The most direct route to the formation of PCTA/DTs is the gas-phase reaction from chemical precursors. Among different precursors, chlorothiophenols (CTPs) are the most direct precursors of PCTA/DTs [20-22], which have been widely used in large quantities in various chemical industries, such as in manufacturing of dyes, insecticides, printing inks, pharmaceuticals, and polyvinyl chloride [23]. Similar to the formation of PCDD/DFs from chlorophenol $(\mathrm{CP})$ precursors, the gas-phase formation of PCTA/DTs from CTP precursors was also proposed involving radical-radical coupling of two CTPRs and radical-molecule recombination of CTPR and CTP [21,22,24-28]. Dar et al. have shown that radical-radical coupling is more competitive thermodynamically than radical-molecule recombination for PCTA/DT formation [21,22,24]. The principal work located the radical-radical coupling to form PCTA/DTs on the condensation of two CTPRs $[21,22,24]$. One study in our group has shown the homogeneous gas-phase formation mechanism of PCTA/DTs from the coupling of 2,4-dichlorothiophenoxy radicals (2,4-DCTPR) and coupling of 2,4,6-trichlorothiophenoxy radicals (2,4,6-TCTPR) [29]. Recently, Yu et al. have proposed that besides CTPRs, various similar radicals including sulfydryl-substituted phenyl radicals and thiophenoxyl diradicals may also be key intermediates in the formation process of PCTA/DTs from CTPs [30]. The homogeneous gas-phase self- and cross- dimerization of these radicals as well as CTPRs could be the initial and important step for the formation of PCTA/DTs [30]. Although sulfydryl-substituted phenyl radicals and thiophenoxyl diradicals have not yet been identified in combustion and thermal processes, their oxygenated counterparts phenyl radicals and phenoxyl diradical have been detected and proposed to be highly active and have great potential for the gas-phase formation of PCDD/DFs [31-35]. A theoretical study by Pan et al. has also proved the formation feasibility of phenyl radicals and phenoxyl diradicals and their energetically favorable contribution to PCDD/DF formation [36]. The structure similarity and high concentration correlation between PCTA/DTs and PCDD/DFs in the environmental samples unsurprisingly revealed their analogous formation mechanism under pyrolysis or combustion conditions $[15,37,38]$. These experimental results have urged us to conjecture similar operating reactions for PCTA/DT formation from CTPRs, sulfydryl-substituted phenyl radicals and thiophenoxyl diradicals as precursors or key intermediates based on PCDD/DF formation from CPRs, phenyl radicals and phenoxyl diradicals as precursors in essentially all proposed pathways [36]. Under the pyrolysis or combustion conditions, CTPRs can be formed through loss of the thiophenoxyl-H, sulfydryl-substituted phenyl radicals can be derived from dissociation of the $\mathrm{Cl}$ or $\mathrm{H}$ atom combining with the carbon in the adjacent position of the carbon with -SH group, and the thiophenoxyl diradical are sourced from the loss of both the triophenoxyl- $\mathrm{H}$ and the ortho-substituted $\mathrm{Cl}$ or $\mathrm{H}$ atom via unimolecular, bimolecular, or possibly other low-energy pathways (including heterogenous reactions). The bimolecular reactions include attack by $\mathrm{H}, \mathrm{OH}, \mathrm{O}\left({ }^{3} \mathrm{P}\right)$, or $\mathrm{Cl}$ under high-temperature oxidative conditions. Yu's study mainly 
focused on the formation of CTPR, sulfydryl-substituted phenyl radical and thiophenoxyl diradical from the abstraction of 2-chlorophenol (2-CP) by $\mathrm{H}$, and studied the subsequent PCTA/DT formation pathways by two representative radical-radical coupling reactions [30]. Therefore, a detailed PCTA/DT formation mechanism from self-/cross- coupling of CTPR, sulfydryl-substituted phenyl radical and thiophenoxyl diradical are needed for further investigation to verify the contributions to PCTA/DT formation of these radicals.

In this paper, we present a systematic theoretical study on the PCTA/DT formation mechanism from 2,4-dichlorothiophenol (2,4-DCTP) as precursor by the self-/cross- condensation of 2,4-dichlorothiophenoxy radical (R1), 2-sulfydryl-3,5-dichlorophenyl radical (R2) and 3,5-dichlorothiophenoxyl diradical (DR). 2,4-DCTP was selected as the model because it has the minimum number of $\mathrm{Cl}$ atoms to form 2,4,6,8-TeCDT, which was the most widely detected and important PCTA/DTs in the environment. In addition, as part of our ongoing work on PCTA/DT from $\mathrm{R} 1+\mathrm{R} 1$ coupling, we compared the R1 + R2, R1 + DR, R2 + DR, R2 + R2 and DR + DR coupling pathways in this study with the R1 + R1 coupling routes in our previous work [29], and sorted all these coupling reactions to confirm their contribution to the formation of PCTA/DTs. Furthermore, the kinetic data and rate constants were evaluated over a wide temperature range of 600-1200 K and fitted into Arrhenius formulas to improve and optimize PCTA/DT formation mathematic models.

\section{Results}

The reliability and accuracy of the MPWB1K/6-311+G(3df,2p)// MPWB1K/6-31+G(d,p) level for the geometries, frequencies and energy calculation in this study have been confirmed in our previous works on PCTA/DT formation with 2,4-DCTP as the precursor [29,39]. The data was compared with data from $Y u$ and Pan calculated at the BB1K/6-311+G(3df,2p)//BB1K/6-311G(d,p) level $[30,36]$. Several typical elementary reactions in this study were calculated at the same level shown in Table S1 of Supplementary Materials. The calculated results in this study agree well with the $\mathrm{BB} 1 \mathrm{~K} / 6-311+\mathrm{G}(3 \mathrm{df}, 2 \mathrm{p}) / / \mathrm{BB} 1 \mathrm{~K} / 6-311 \mathrm{G}(\mathrm{d}, \mathrm{p})$ values (the relative deviation remains within $0.48 \mathrm{kcal} / \mathrm{mol}$ for potential barriers and $1.19 \mathrm{kcal} / \mathrm{mol}$ for reaction heats). The imaginary frequencies, the zero-point energies and the total energies for the transition states involved in the formation of PCTA/DTs from R1, R2 and DR are shown in Table S2. Cartesian coordinates for the reactants, intermediates, transition states and products involved in formation of PCTA/DTs from R1, R2 and DR are depicted in Tables S4 and S5.

\subsection{Formation of 2,4-Dichlorothiophenoxy Radical R1, 2-Sulfydryl-3,5-Dichlorophenyl Radical R2 and 3,5-Dichlorothiophenoxyl Diradical DR}

The formation of 2,4-dichlorothiophenoxy radical (R1), 2-sulfydryl-3,5-dichlorophenyl radical (R2) and 3,5-dichlorothiophenoxyl diradical (DR) which derive from 2,4-DCTP is the initial and key step in the formation of PCTA/DTs. These radicals may be generated by the bimolecular reaction of 2,4-DCTP with the active radicals $\mathrm{H}, \mathrm{OH}$ and $\mathrm{Cl}$ which exist abundantly in combustion and thermal processes. The calculated potential barriers $(\Delta E)$ and the reaction heats $(\Delta H)$ at the MPWB1K/6-311+G(3df,2p)//MPWB1K/6-31+G(d,p) level involved in the formation of R1, R2 and DR radicals from 2,4-DCTP abstracted by the $\mathrm{OH}, \mathrm{H}$ and $\mathrm{Cl}$ are given in the Figure 1a-c. In Figure 1, data of 2,4-DCTP thiophenoxyl- $\mathrm{H}$ abstraction by $\mathrm{OH}$ and $\mathrm{H}$ were cited from our previous studies [39]. All the optimized transition state geometries for 2,4-DCTP abstracted by $\mathrm{OH}, \mathrm{H}$ and $\mathrm{Cl}$ radicals are shown in Figure 2. 
a)

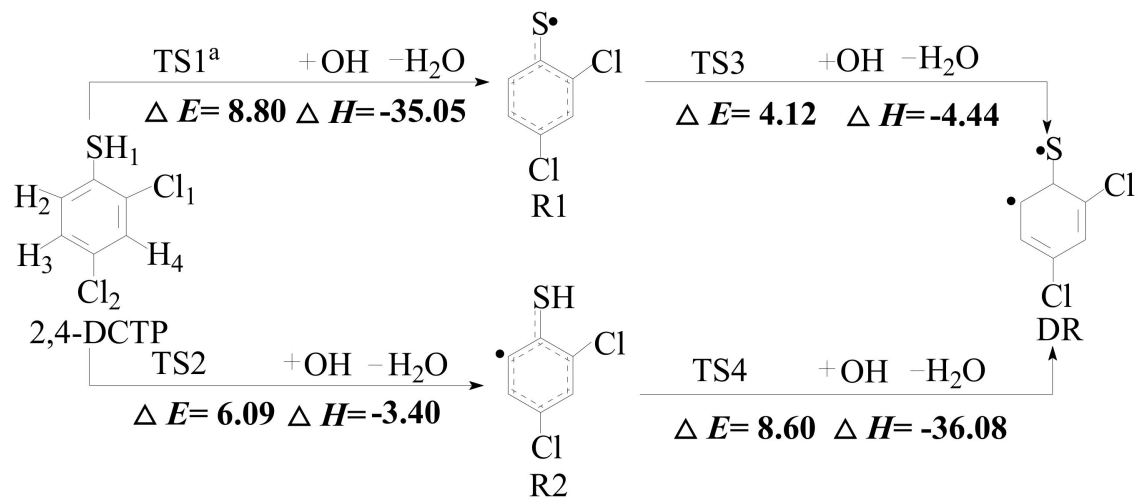

b)

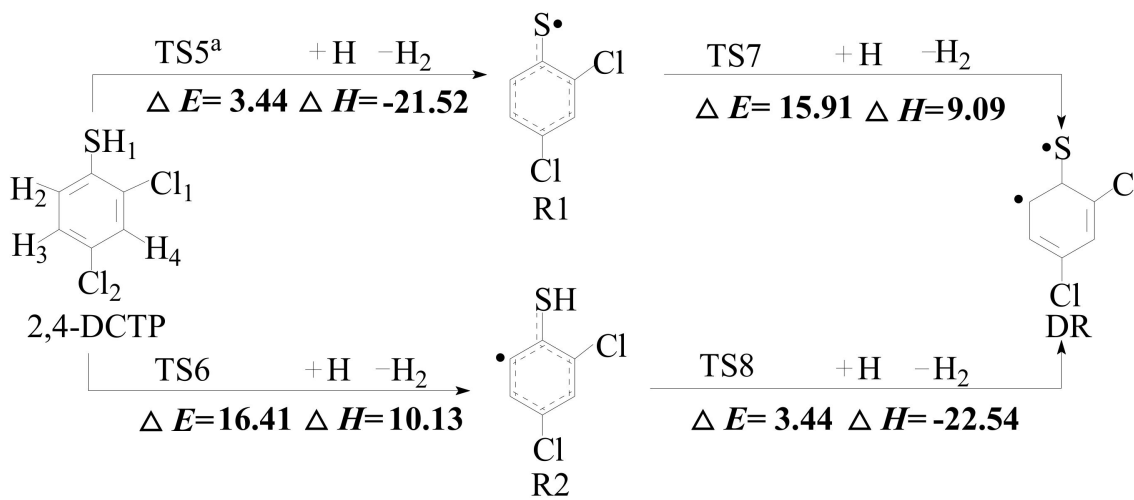

c)
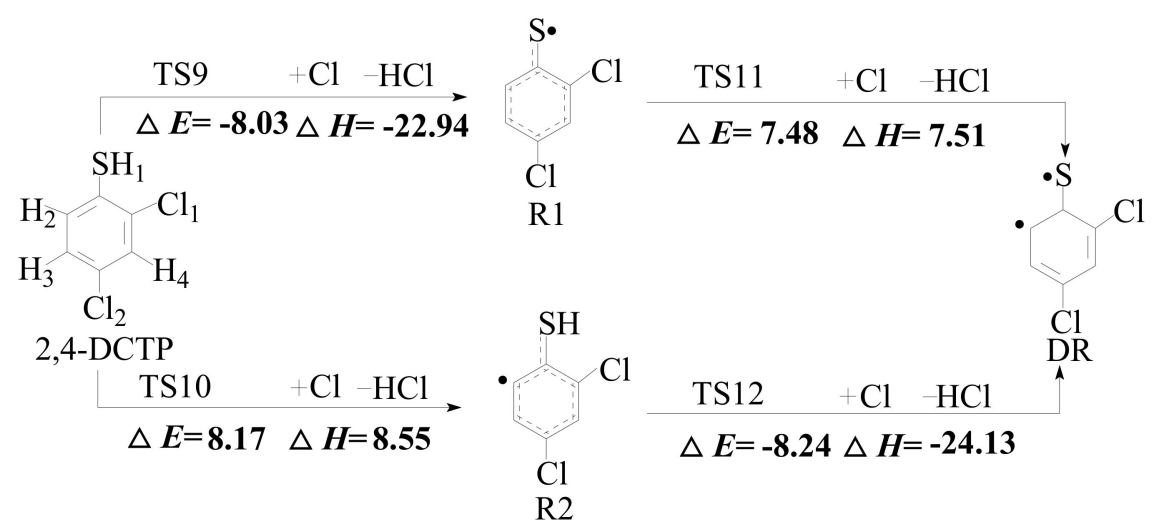

Figure 1. Schematic formation of various radicals from the reactions of 2,4-DCTP with $\mathrm{OH}(\mathbf{a}), \mathrm{H}(\mathbf{b})$ and $\mathrm{Cl}$ (c) with the potential barriers $\Delta E$ (in kcal $/ \mathrm{mol}$ ) and reaction heats $\Delta H$ (in kcal $/ \mathrm{mol}$ ). ( ${ }^{\text {a }}$ Reproduced with permission from $\mathrm{Xu}$ et al. [39]).

In Figure 1, the sulfydryl group $\mathrm{H}$ atom in 2,4-DCTP is labeled as $\mathrm{H} 1$, the extra three $\mathrm{H}$ atom at the benzene ring are numbered as $\mathrm{H} 2-\mathrm{H} 4$, and two $\mathrm{Cl}$ atoms at the benzene ring are numbered as $\mathrm{Cl} 1$ and $\mathrm{Cl} 2$. The $\mathrm{R} 1$ radical can be produced through loss of the thiophenoxyl-hydrogen (H1) abstracted by $\mathrm{H}, \mathrm{OH}$ and $\mathrm{Cl}$ radicals. The $\mathrm{R} 2$ radical can be formed through elimination of the thiophenyl-hydrogen (H2). As mentioned by Yu et al. [30], five chlorinated thiophenyl radicals can be formed by abstracting $\mathrm{H} 2-\mathrm{H} 4$ and $\mathrm{Cl} 1-\mathrm{Cl} 2$, but only two chlorinated thiophenyl radicals losing ortho $\mathrm{H}$ or $\mathrm{Cl}(\mathrm{H} 2$ or $\mathrm{Cl} 1)$ can further react to form PCTA/DTs [30,40]. In addition, chlorinated thiophenyl radical losing $\mathrm{H} 2$ contribute to the formation 2,4,6,8-TeCDT, which must be produced from 2,4-DCTP without $\mathrm{Cl}$ loss. Thus, only one chlorinated thiophenyl radical $\mathrm{R} 2$ formed by abstracting $\mathrm{H} 2$ is further studied in this paper. The DR radical can be generated by fission of both thiophenoxyl-hydrogen and thiophenyl-hydrogen (H1 and $\mathrm{H} 2$ ). 


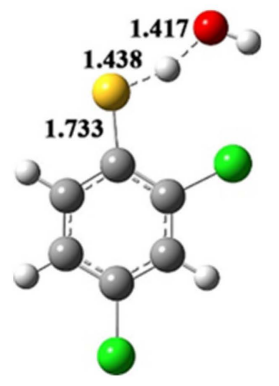

TS1
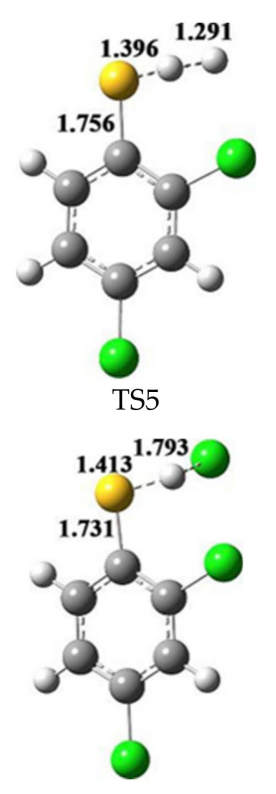

TS9

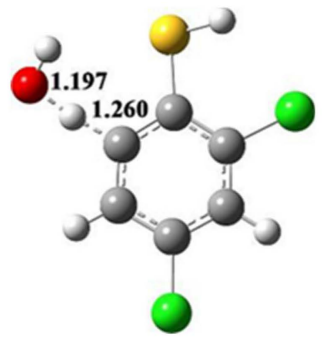

TS2
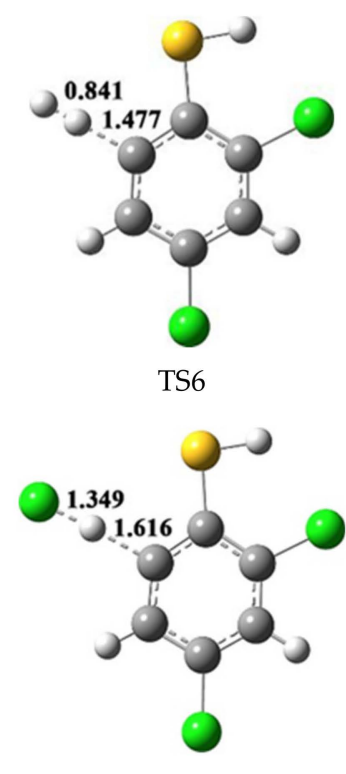

TS10

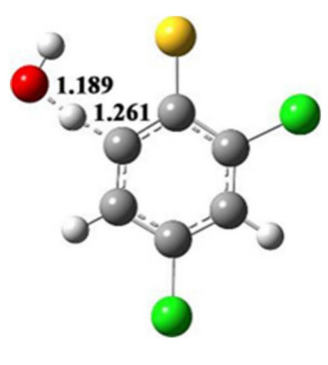

TS3
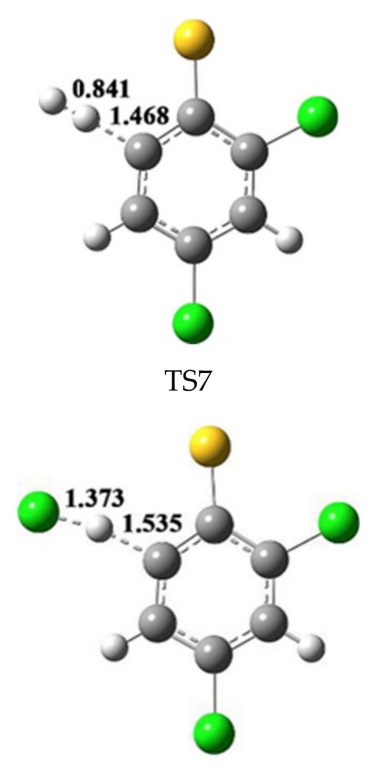

TS11
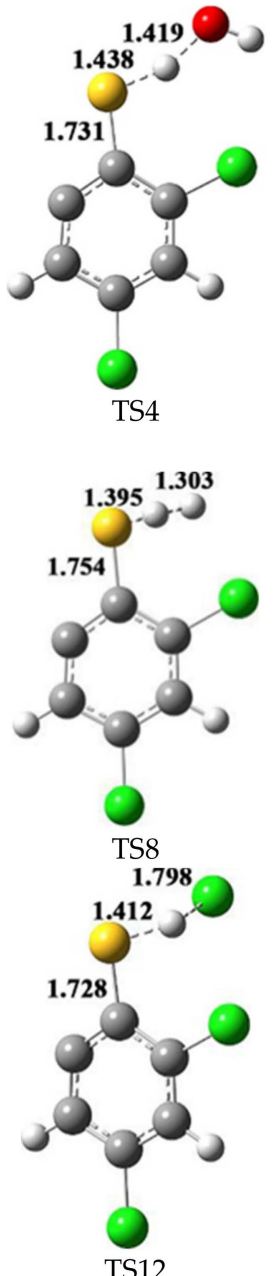

Figure 2. MPWB1K/6-31+G(d,p) optimized transition state geometries for reactions between 2,4-DCTP with $\mathrm{OH}, \mathrm{H}$ and $\mathrm{Cl}$ radicals. The bond distances are given in $\AA$. Green, gray, yellow, red and white balls denote $\mathrm{Cl}, \mathrm{C}, \mathrm{S}, \mathrm{O}$ and $\mathrm{H}$ atoms, respectively.

\subsection{Formation of PCTAs from $R 1, R 2$ and $D R$}

Figure 3 illustrates schematically the proposed reaction pathways for the formation of PCTAs from radical-radical cross-condensation R1 + R2 (in Figure 3a), R1 + DR (in Figure $3 b$ ) and $R 2+D R$ (in Figure 3c), and self-condensation of DR + DR (in Figure 3d). The potential barriers $\Delta E$ (in $\mathrm{kcal} / \mathrm{mol}$ ) and reaction heats $\Delta H$ (in $\mathrm{kcal} / \mathrm{mol}$ ) are calculated at the MPWB1K/6-311+G(3df,2p)//MPWB1K/6-31+G(d,p) level. As shown in Figure 3, ten possible pathways, denoted as pathways 1-10, are postulated, resulting in five PCTA congeners (1,3,8-TCTA, 1,3,7-TCTA, 1,3,6,8-TeCTA, 1,3,7,9-TeCTA and 2,4,7,9-TeCTA). Among them, pathway 1 to pathway 8 from R1 + R2 and R1 + DR converge to a common intermediate, IM5, which also lies in the self-coupling of 2,4-dichlorothiophenol (R1 + R1) in our previous paper [29]. 


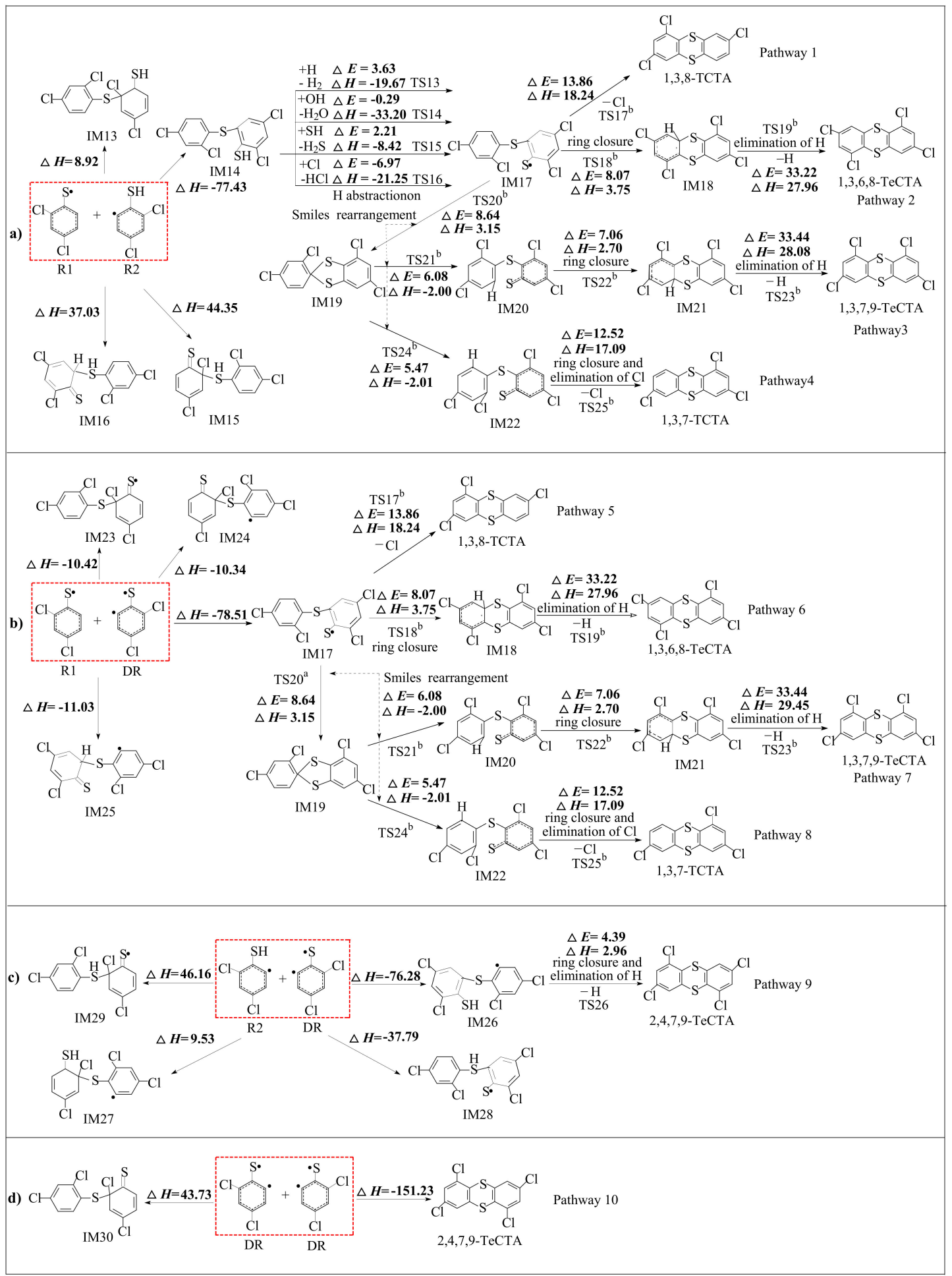

Figure 3. Polychlorinated thianthrene (PCTA) formation routes embedded with the potential barriers $\Delta E$ (in $\mathrm{kcal} / \mathrm{mol}$ ) and reaction heats $\Delta H$ (in $\mathrm{kcal} / \mathrm{mol}$ ) from self- and cross-couplings of $\mathrm{R} 1+\mathrm{R} 2$ (a), $\mathrm{R} 1+\mathrm{DR}(\mathbf{b}), \mathrm{R} 2+\mathrm{DR}(\mathbf{c})$, and DR + DR (d). $\Delta H$ is calculated at $0 \mathrm{~K}$. ( ${ }^{\mathrm{b}}$ Reproduced with permission from $\mathrm{Xu}$ et al. [29]).

In R1 + R2 route in Figure 3a, the cross-coupling of R1 + R2 leads to the formation of IM1, IM2, IM3 and IM4 from four kinds of sulfur-carbon coupling modes: (1) The coupling of the thiophenolic sulfur bonded to single electron with the ortho carbon bonded to chlorine of the chlorothiophenyl

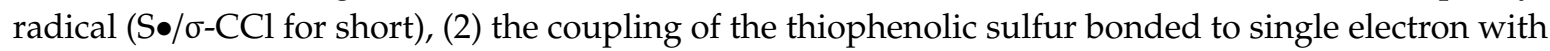


the ortho carbon bonded to single electron of the chlorothiophenyl radical ( $\mathrm{S} \bullet / \sigma-\mathrm{C} \bullet$ for short), (3) the coupling of the thiophenolic sulfur bonded to hydrogen of the chlorothiophenyl radical with the ortho carbon bonded to chlorine of the chlorothiophenoxy radical ( $\mathrm{SH} / \sigma-\mathrm{CCl}$ for short), and (4) the coupling of the thiophenolic sulfur of the chlorothiophenyl radical bonded to hydrogen with the ortho carbon bonded to hydrogen of the chlorothiophenoxy radical $(\mathrm{SH} / \sigma-\mathrm{CH}$ for short). And it can be seen from Figure 3a that pathway 1 involves three elementary steps: (1) sulfur-carbon coupling; (2) H abstraction and (3) ring closure and intra-annular elimination of $\mathrm{Cl}$. The ring closure and intra-annular elimination of $\mathrm{Cl}$ occur in a one-step reaction and are the concerted reactions. From Figure 3a, pathway 2 contains four elementary pathways: (1) sulfur-carbon coupling; (2) $\mathrm{H}$ abstraction; (3) ring closure and (4) intra-annular elimination of $\mathrm{H}$. The ring closure and elimination of $\mathrm{H}$ steps occur separately. Pathway 3 and Pathway 4 include two smiles rearrangement steps before ring closure step compared to pathway 2 and Pathway 1 and has six elementary steps and five elementary steps, respectively.

In Figure 3b, the cross-coupling reaction of R1 + DR also yield four intermediates (IM5, IM11,

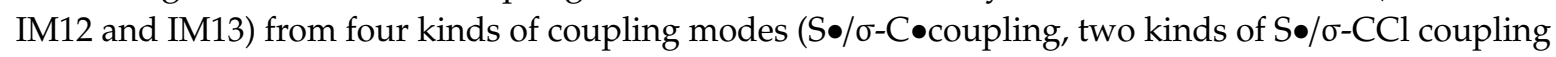
and $\mathrm{S} \bullet / \sigma-\mathrm{CH}$ coupling), respectively. From Figure $3 \mathrm{c}$, there are four kinds of cross-coupling modes of $\mathrm{R} 2+\mathrm{DR}(\mathrm{S} \bullet / \sigma-\mathrm{C} \bullet$ coupling, $\mathrm{S} \bullet / \sigma-\mathrm{CCl}$ coupling, $\mathrm{SH} / \sigma-\mathrm{CCl}$ coupling and $\mathrm{SH} / \sigma-\mathrm{C} \bullet$ coupling), which generates IM14, IM15, IM16 and IM17. Owning to the symmetry of self-coupling of DR + DR, there are only two sulfur-carbon coupling modes in Figure $3 \mathrm{~d}$ : $\mathrm{S} \bullet / \sigma-\mathrm{C} \bullet$ couplings and $\mathrm{S} \bullet / \sigma-\mathrm{CCl}$ couplings. Besides the ten pathways, we also studied the PCTA formation of R2 + R2 coupling in Figure S1 of Supplementary Materials. There are two sulfur-carbon coupling modes in R2 + R2 coupling, which includes $\mathrm{SH} / \sigma-\mathrm{CCl}$ coupling and $\mathrm{SH} / \sigma-\mathrm{C} \bullet$ coupling.

\subsection{Formation of $P C D T$ from $R 1, R 2$ and $D R$}

Figure 4 depicts the homogeneous gas-phase formation mechanisms of PCDTs from radical-radical cross-condensation R1 + R2 (in Figure 4a), R1 + DR (in Figure 4b) and R2 + DR (in Figure 4c), and self-condensation of $\mathrm{R} 2+\mathrm{R} 2$ (in Figure $4 \mathrm{~d}$ ). Five formation pathways are postulated to explain two PCDT congeners (2,4,6,8-TeCDT and 2,6,8-TCDT) formations in Figure 4. Among them, pathway 11, 13,14 and 15 from R1 + R2, R1 + DR, R2 + DR and R2 + R2 converged to a common intermediate, IM23, which are identified as the pre-intermediate of 2,4,6,8-TeCDT. In our previous paper, self-coupling of 2,4-dichlorothiophenol (R1 + R1) can also form IM23, which creates analogously consequent reactions to form 2,4,6,8-TeCDT [29]. Pathway 12 are proposed to interpret the formation of 2,6,8-TCDT, and has the identical pre-intermediate IM25 compared with the 2,6,8-TCDT formation pathway from self-coupling of 2,4-dichlorothiophenol (R1 + R1) [29]. Several typical optimized transition state geometries in the formation of PCTA/DTs are shown in Figure 5. 


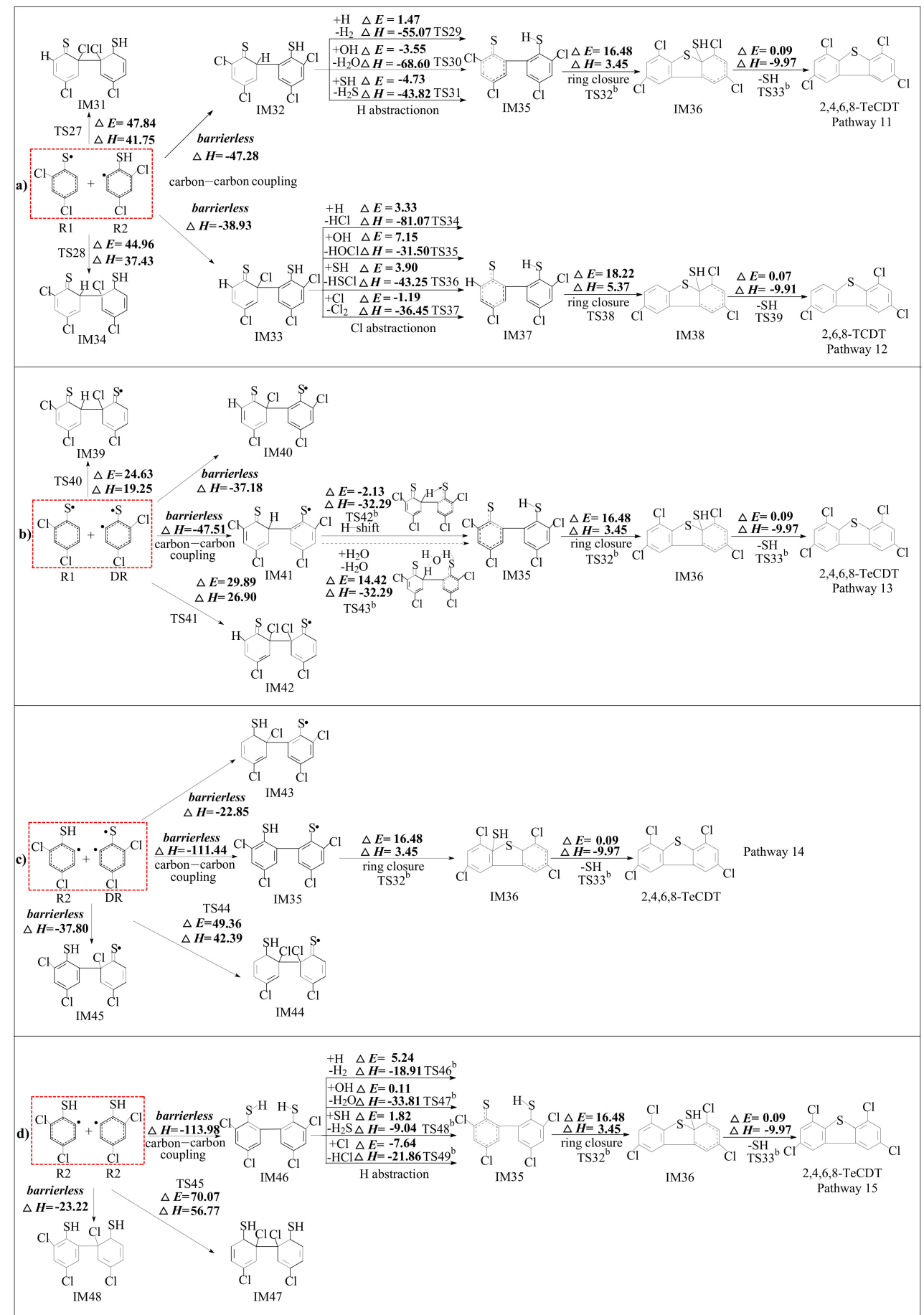

Figure 4. Polychlorinated dibenzothiophene (PCDT) formation routes embedded with the potential barriers $\Delta E$ (in kcal $/ \mathrm{mol}$ ) and reaction heats $\Delta H$ (in kcal $/ \mathrm{mol}$ ) from self- and cross-couplings of $\mathrm{R} 1+\mathrm{R} 2$ (a), R1 + DR (b), R2 + DR (c), and R2 + R2 (d). $\Delta H$ is calculated at $0 \mathrm{~K}$. ( ${ }^{\mathrm{b}}$ Reproduced with permission from $\mathrm{Xu}$ et al. [29]). 


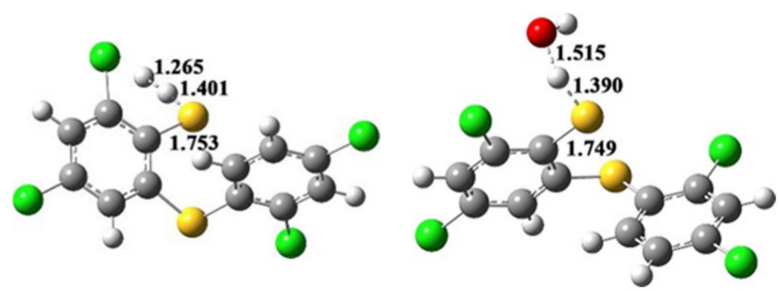

TS13

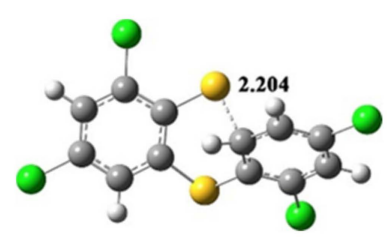

TS18

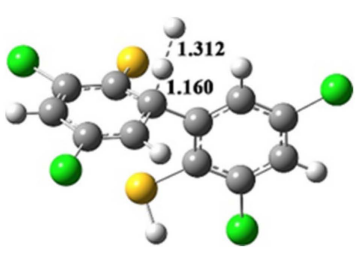

TS29

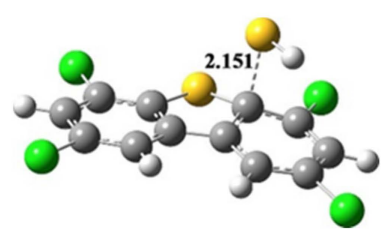

TS33
TS14

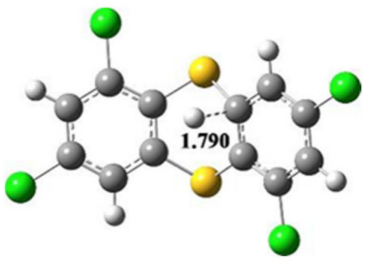

TS19

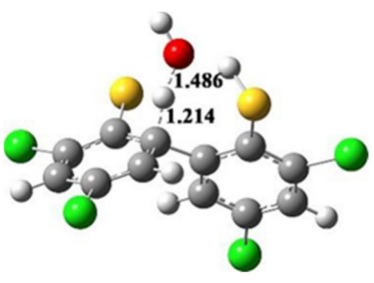

TS30

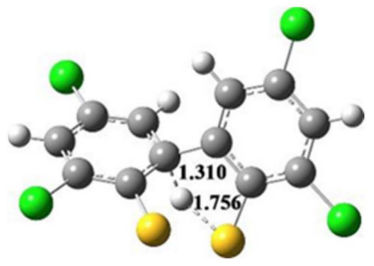

TS42

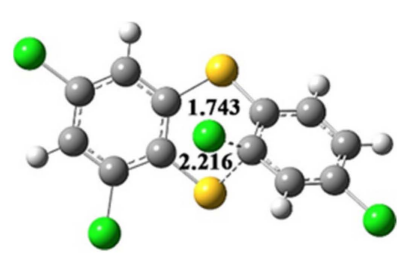

TS17

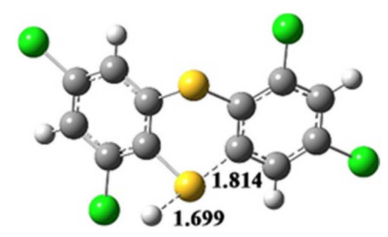

TS26

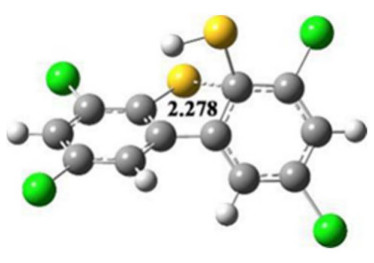

TS32

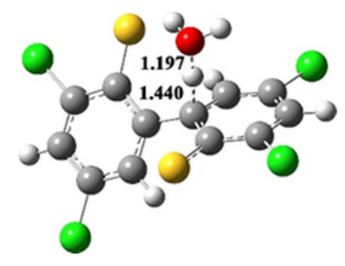

TS43

Figure 5. MPWB1K/6-31+G(d,p) optimized transition state geometries in the formation of PCTA/DTs. The bond distances are given in $\AA$. Green, gray, yellow, red and white balls denote $\mathrm{Cl}, \mathrm{C}, \mathrm{S}, \mathrm{O}$ and $\mathrm{H}$ atoms, respectively.

In Figure 4a, the coupling reaction of R1 + R2 leads to the formation of IM19, IM20, IM21 and IM22 from four kinds of coupling modes: (1) The coupling of ortho carbon bonded to chlorine of R1 with the ortho carbon bonded to chlorine of $\mathrm{R} 2(\sigma-\mathrm{CCl} / \sigma-\mathrm{CCl}$ for short); (2) the coupling of ortho carbon bonded to hydrogen of R1 with the ortho carbon bonded to single electron of $\mathrm{R} 2$ ( $\sigma-\mathrm{CH} / \sigma-\mathrm{C} \bullet$ for short); (3) the coupling of ortho carbon bonded to chlorine of R1 with the ortho carbon bonded to single electron of R2 ( $\sigma-\mathrm{CCl} / \sigma-\mathrm{C} \bullet$ for short) and (4) the coupling of ortho carbon bonded to hydrogen of R1 with the ortho carbon bonded to chlorine of $\mathrm{R} 2(\sigma-\mathrm{CH} / \sigma-\mathrm{CCl}$ for short). In Figure 4a, both pathways 11 and 12 involve four elementary steps: (1) carbon-carbon coupling; (2) $\mathrm{H} / \mathrm{Cl}$ abstraction; (3) ring closure and (4) elimination of $\mathrm{SH}$. The $\mathrm{H} / \mathrm{Cl}$ abstraction step can proceed due to being abstracted by $\mathrm{H}, \mathrm{OH}, \mathrm{SH}$ and $\mathrm{Cl}$ radicals.

In Figure $4 b$, the coupling reactions of R1 + DR also produce four intermediates (IM27, IM28, IM29 and IM30) from four kinds of coupling modes. The formation of IM27 is from $\sigma-\mathrm{CH} / \sigma-\mathrm{CCl}$ coupling and formation of IM30 is from $\sigma-\mathrm{CCl} / \sigma-\mathrm{CCl}$ coupling. And the formation of IM28 is from $\sigma-\mathrm{CCl} / \sigma-\mathrm{C} \bullet$ coupling and formation of IM29 is from $\sigma-\mathrm{CH} / \sigma-\mathrm{C} \bullet$ coupling. In Figure $4 \mathrm{~b}$, pathway 13 is comprised of four elementary steps: (1) carbon-carbon coupling; (2) H shift (without and with water); (3) ring closure and (4) elimination of SH. The rate-determining step occurs in the ring closure step. As shown in Figure 4 b, water molecular can participate actively in the $\mathrm{H}$ shift step though 
forming a seven-membered water bridge ring, which accepts the $\mathrm{H}$ from the aromatic ring and simultaneously donates another $\mathrm{H}$ atom to the $\mathrm{S}$ atom. The $\mathrm{R} 2+\mathrm{DR}$ route involves four kind of coupling modes resulting in the formation of IM23, IM31, IM32 and IM33 in Figure 4c. Pathway 14 covers three elementary processes to form 2,4,6,8-TeCDT: (1) carbon-carbon coupling; (2) ring closure and (3) elimination of SH. And there exists a new coupling mode (the coupling of ortho carbon bonded to single electron of R2 with the ortho carbon bonded to single electron of DR ( $\sigma-\mathrm{C} \bullet / \sigma-\mathrm{C} \bullet$ for short)), which leads to the formation of IM23. The R2 + R2 can proceed to self-coupling, which results in IM34, IM35 and IM36 as depicted in Figure 4d.

\subsection{Rate Constant Calculations}

The kinetic parameters, such as the pre-exponential factor, the activation energy, and the rate constants of the elementary reactions of PCTA/DT formation are significant for constructing the formation kinetic model to predict the potential emissions and poisonousness to the environment. Thus, the rate constants of the crucial elementary reactions in the formation of the PCTA/DTs from $\mathrm{R} 1, \mathrm{R} 2$ and DR were calculated by using canonical variational transition state theory (CVT) with small-curvature tunneling (SCT) contribution methods in the temperature range of 600-1200 K relevant to real situations at high temperature PCTA/DT formation conditions [41-44]. The results are shown in Table S3 of Supplementary Materials.

To be applied more effectively, the CVT/SCT rate constants were fitted, and Arrhenius formulas are given in Table 1 for the elementary reactions involved in the formation of PCTA/DTs from R1, $\mathrm{R} 2$ and DR. The pre-exponential factor, the activation energy, and the rate constants can be obtained from these Arrhenius formulas.

Table 1. Arrhenius formulas for crucial elementary reactions involved in the formation of R1, R2 and DR from the 2,4-DCTP precursor and PCTA/DTs from the R1, R2 and DR precursors over the temperature range of $600-1200 \mathrm{~K}$. (units are $\mathrm{s}^{-1}$ and $\mathrm{cm}^{3}$ molecule $\mathrm{e}^{-1} \mathrm{~s}^{-1}$ for unimolecular and bimolecular reactions, respectively. ${ }^{a}$ Reproduced with permission from $\mathrm{Xu}$ et al. [39], ${ }^{\mathrm{b}}$ Reproduced with permission from Xu et al. [29]).

\begin{tabular}{|c|c|}
\hline Reactions Arrhenius Formulas & Arrhenius Formulas \\
\hline 2,4-DCTP $+\mathrm{OH} \rightarrow \mathrm{R} 1+\mathrm{H}_{2} \mathrm{O}$ via TS1 ${ }^{\mathrm{a}}$ & $k(\mathrm{~T})=\left(6.69 \times 10^{-14}\right) \exp (-5861 / \mathrm{T})$ \\
\hline 2,4-DCTP $+\mathrm{OH} \rightarrow \mathrm{R} 2+\mathrm{H}_{2} \mathrm{O}$ via TS2 & $k(\mathrm{~T})=\left(1.07 \times 10^{-15}\right) \exp (-12857 / \mathrm{T})$ \\
\hline $\mathrm{R} 1+\mathrm{OH} \rightarrow \mathrm{DR}+\mathrm{H}_{2} \mathrm{O}$ via TS3 & $k(\mathrm{~T})=\left(7.18 \times 10^{-12}\right) \exp (-3795 / \mathrm{T})$ \\
\hline $\mathrm{R} 2+\mathrm{OH} \rightarrow \mathrm{DR}+\mathrm{H}_{2} \mathrm{O}$ via TS4 & $k(\mathrm{~T})=\left(3.19 \times 10^{-13}\right) \exp (-3630 / \mathrm{T})$ \\
\hline 2,4-DCTP $+\mathrm{H} \rightarrow \mathrm{R} 1+\mathrm{H}_{2}$ via TS5 ${ }^{a}$ & $k(\mathrm{~T})=\left(2.84 \times 10^{-11}\right) \exp (-2229 / \mathrm{T})$ \\
\hline 2,4-DCTP + H $\rightarrow \mathrm{R} 2+\mathrm{H}_{2}$ via TS6 & $k(\mathrm{~T})=\left(9.24 \times 10^{-11}\right) \exp (-8977 / \mathrm{T})$ \\
\hline $\mathrm{R} 1+\mathrm{H} \rightarrow \mathrm{DR}+\mathrm{H}_{2}$ via TS7 & $k(\mathrm{~T})=\left(6.55 \times 10^{-11}\right) \exp (-8600 / \mathrm{T})$ \\
\hline $\mathrm{R} 2+\mathrm{H} \rightarrow \mathrm{DR}+\mathrm{H}_{2}$ via TS8 & $k(\mathrm{~T})=\left(3.99 \times 10^{-12}\right) \exp (-1331 / \mathrm{T})$ \\
\hline $2,4-\mathrm{DCTP}+\mathrm{Cl} \rightarrow \mathrm{R} 2+\mathrm{HCl}$ via TS10 & $k(\mathrm{~T})=\left(1.52 \times 10^{-10}\right) \exp (-5852 / \mathrm{T})$ \\
\hline $\mathrm{R} 1+\mathrm{Cl} \rightarrow \mathrm{DR}+\mathrm{HCl}$ via TS11 & $k(\mathrm{~T})=\left(1.47 \times 10^{-10}\right) \exp (-5978 / \mathrm{T})$ \\
\hline $\mathrm{IM} 2+\mathrm{H} \rightarrow \mathrm{IM} 5+\mathrm{H}_{2}$ via TS13 & $k(\mathrm{~T})=\left(3.53 \times 10^{-11}\right) \exp (-2623 / \mathrm{T})$ \\
\hline $\mathrm{IM} 2+\mathrm{SH} \rightarrow \mathrm{IM} 5+\mathrm{H}_{2} \mathrm{~S}$ via TS15 & $k(\mathrm{~T})=\left(8.24 \times 10^{-13}\right) \exp (-3080 / \mathrm{T})$ \\
\hline $\mathrm{IM} 5 \rightarrow 1,3,8-\mathrm{TCTA}^{-\mathrm{Cl}}$ via TS17 ${ }^{\mathrm{b}}$ & $k(\mathrm{~T})=\left(4.52 \times 10^{11}\right) \exp (-7140 / \mathrm{T})$ \\
\hline IM5 $\rightarrow$ IM6 via TS18 ${ }^{\text {b }}$ & $k(\mathrm{~T})=\left(6.15 \times 10^{11}\right) \exp (-4332 / \mathrm{T})$ \\
\hline $\mathrm{IM} 6 \rightarrow 1,3,6,8-\mathrm{TeCTA}+\mathrm{H}$ via TS19 $\mathrm{b}$ & $k(\mathrm{~T})=\left(2.84 \times 10^{13}\right) \exp (-17667 / \mathrm{T})$ \\
\hline IM14 $\rightarrow 2,4,7,9-\mathrm{TeCTA}+\mathrm{H}$ via TS26 & $k(\mathrm{~T})=\left(4.52 \times 10^{11}\right) \exp (-2395 / \mathrm{T})$ \\
\hline $\mathrm{IM} 20+\mathrm{H} \rightarrow \mathrm{IM} 23+\mathrm{H}_{2}$ via TS29 & $k(\mathrm{~T})=\left(1.00 \times 10^{-11}\right) \exp (-1531 / \mathrm{T})$ \\
\hline IM23 $\rightarrow$ IM24 via TS32 ${ }^{\mathrm{b}}$ & $k(\mathrm{~T})=\left(3.07 \times 10^{11}\right) \exp (-8241 / \mathrm{T})$ \\
\hline IM24 $\rightarrow$ 2,4,6,8-TeCDT + SH via TS33 b & $k(\mathrm{~T})=\left(5.86 \times 10^{12}\right) \exp (-351 / \mathrm{T})$ \\
\hline $\mathrm{IM} 21+\mathrm{H} \rightarrow \mathrm{IM} 25+\mathrm{HCl}$ via TS34 & $k(\mathrm{~T})=\left(9.78 \times 10^{-11}\right) \exp (-2502 / \mathrm{T})$ \\
\hline $\mathrm{IM} 21+\mathrm{OH} \rightarrow \mathrm{IM} 25+\mathrm{HOCl}$ via TS35 & $k(\mathrm{~T})=\left(1.13 \times 10^{-11}\right) \exp (-12954 / \mathrm{T})$ \\
\hline $\mathrm{IM} 21+\mathrm{SH} \rightarrow \mathrm{IM} 25+\mathrm{HSCl}$ via TS36 & $k(\mathrm{~T})=\left(4.82 \times 10^{-12}\right) \exp (-3861 / \mathrm{T})$ \\
\hline IM25 $\rightarrow$ IM26 via TS38 & $k(\mathrm{~T})=\left(7.61 \times 10^{11}\right) \exp (-9275 / \mathrm{T})$ \\
\hline IM26 $\rightarrow 2,6,8-\mathrm{TCDT}+\mathrm{SH}$ via TS39 & $k(\mathrm{~T})=\left(8.96 \times 10^{12}\right) \exp (-275 / \mathrm{T})$ \\
\hline $\mathrm{IM} 29+\mathrm{H}_{2} \mathrm{O} \rightarrow \mathrm{IM} 23+\mathrm{H}_{2} \mathrm{O}$ via TS43 ${ }^{\mathrm{b}}$ & $k(\mathrm{~T})=\left(3.20 \times 10^{-15}\right) \exp (-3310 / \mathrm{T})$ \\
\hline $\mathrm{IM} 34+\mathrm{H} \rightarrow \mathrm{IM} 23+\mathrm{H}_{2}$ via TS46 & $k(\mathrm{~T})=\left(5.71 \times 10^{-9}\right) \exp (-1148 / \mathrm{T})$ \\
\hline $\mathrm{IM} 34+\mathrm{OH} \rightarrow \mathrm{IM} 23+\mathrm{H}_{2} \mathrm{O}$ via TS $47 \mathrm{~b}$ & $k(\mathrm{~T})=\left(7.66 \times 10^{-12}\right) \exp (-1889 / \mathrm{T})$ \\
\hline $\mathrm{IM} 34+\mathrm{SH} \rightarrow \mathrm{IM} 23+\mathrm{H}_{2} \mathrm{~S}$ via TS48 ${ }^{\mathrm{b}}$ & $k(\mathrm{~T})=\left(1.10 \times 10^{-12}\right) \exp (-2808 / \mathrm{T})$ \\
\hline
\end{tabular}




\section{Discussion}

3.1. Formation of 2,4-Dichlorothiophenoxy Radical R1, 2-Sulfydryl-3,5-Dichlorophenyl Radical R2 and 3,5-Dichlorothiophenoxyl Diradical DR

In Figure 1, for the formation of R1, the potential barrier of $\mathrm{H} 1$ abstraction of 2,4-DCTP by $\mathrm{OH}$, $\mathrm{H}$ and $\mathrm{Cl}$ radicals is $8.80 \mathrm{kcal} / \mathrm{mol}, 3.44 \mathrm{kcal} / \mathrm{mol}$ and $-8.03 \mathrm{kcal} / \mathrm{mol}$, respectively. Similarly, for the formation of R2, the potential barrier of $\mathrm{H} 2$ abstraction of 2,4-DCTP abstracted by $\mathrm{OH}, \mathrm{H}$ and $\mathrm{Cl}$ radicals is $6.09 \mathrm{kcal} / \mathrm{mol}, 16.41 \mathrm{kcal} / \mathrm{mol}$ and $8.17 \mathrm{kcal} / \mathrm{mol}$, respectively. Apparently, the formation of $\mathrm{R} 1$ through $\mathrm{H}$ and $\mathrm{Cl}$ abstraction involves lower potential barriers than that of $\mathrm{R} 2$ through $\mathrm{H}$ and $\mathrm{Cl}$, respectively. For the $\mathrm{OH}$ abstraction reactions, the potential barrier of the formation of $\mathrm{R} 2$ is slightly lower than R1. In addition, the formation of $\mathrm{R} 1$ abstracted by $\mathrm{OH}, \mathrm{H}$ and $\mathrm{Cl}(-35.05 \mathrm{kcal} / \mathrm{mol}$, $-21.52 \mathrm{kcal} / \mathrm{mol}$ and $-22.94 \mathrm{kcal} / \mathrm{mol})$ is more exothermic than that of $\mathrm{R} 2$ abstracted by $\mathrm{OH}, \mathrm{H}$ and $\mathrm{Cl}(-3.40 \mathrm{kcal} / \mathrm{mol}, 10.13 \mathrm{kcal} / \mathrm{mol}$ and $8.55 \mathrm{kcal} / \mathrm{mol})$, respectively. These results indicate that R1 is much easier to form and stable than R2, and R2 may be more active and short-lived. From Figure 1, DR can be formed from both R1 and R2. The potential barrier of DR from R1 abstracted by OH, H and $\mathrm{Cl}$ radicals is $4.12 \mathrm{kcal} / \mathrm{mol}, 15.91 \mathrm{kcal} / \mathrm{mol}$ and $7.48 \mathrm{kcal} / \mathrm{mol}$, respectively, while the potential barrier of DR from R2 abstracted by $\mathrm{OH}, \mathrm{H}$ and $\mathrm{Cl}$ radicals is $8.60 \mathrm{kcal} / \mathrm{mol}, 3.44 \mathrm{kcal} / \mathrm{mol}$ and $-8.24 \mathrm{kcal} / \mathrm{mol}$, respectively. Thus, it is evident that DR is more likely to form through $\mathrm{R} 2$ than through $\mathrm{R} 1$ abstracted by $\mathrm{H}$ and $\mathrm{Cl}$ radical, while the order is contrarily abstracted by $\mathrm{OH}$ radical.

Comparing with the values from the formation of 2-chlorinated phenoxy radical, 2-chlorinated phenyl radical and 2-chlorinated phenoxyl diradical from 2-CP with $\mathrm{OH}$ calculated by Pan at $\mathrm{BB} 1 \mathrm{~K} / 6-311+\mathrm{G}(3 \mathrm{df}, 2 \mathrm{p}) / / \mathrm{BB} 1 \mathrm{~K} / 6-311 \mathrm{G}(\mathrm{d}, \mathrm{p})$ level [36], the potential barrier for the formation of R1 from 2,4-DCTP with $\mathrm{OH}$ in this study is higher by $5.30 \mathrm{kcal} / \mathrm{mol}$ than that of 2-chlorinated phenoxy radical formation from 2-CP with $\mathrm{OH}$, while the potential barrier for the formation of R2 from 2,4-DCTP with $\mathrm{OH}$ in this study is higher by $0.39 \mathrm{kcal} / \mathrm{mol}$ than that of 2-chlorinated phenoxy radical formation from 2-CP with $\mathrm{OH}$. This indicates that hydroxyl-H and phenyl-H abstraction in $\mathrm{CP}$ abstraction may process more easily than that of sulfydryl-H and thiophenyl-H abstraction in CTP. In addition, it is also necessary to compare our data with the value from formation of 2-chlorinated thiophenoxy radical, 2-chlorinated thiophenyl radical and 2-chlorinated thiophenoxyl diradical from 2-CTP calculated by Yu at BB1K/6-311+G(3df,2p)//BB1K/6-311G(d,p) level [30]. The formation of DR from R1 in our study can occur with a higher potential barrier by $6.55 \mathrm{kcal} / \mathrm{mol}$ and being more endothermic by $6.96 \mathrm{kcal} / \mathrm{mol}$ than those of formation of 2-chlorinated thiophenoxyl diradical from 2-chlorinated thiophenoxy radical, which implied that the diradical formation could occur with added difficulty with the substitition of $\mathrm{Cl}$ atom in the para-position of CTP.

\subsection{Formation of PCTAs from $R 1, R 2$ and $D R$}

As presented in Figure $3 \mathrm{a}$, the $\mathrm{S} \bullet / \sigma-\mathrm{C} \bullet$ coupling is strongly exothermic $(-77.43 \mathrm{kcal} / \mathrm{mol})$ and other three coupling modes are endothermic $(8.92 \mathrm{kcal} / \mathrm{mol}, 44.35 \mathrm{kcal} / \mathrm{mol}$ and $37.03 \mathrm{kcal} / \mathrm{mol})$. Thus, $\mathrm{S} \bullet / \sigma-\mathrm{C} \bullet$ coupling is thermodynamically preferred to $\mathrm{S} \bullet / \sigma-\mathrm{CCl}, \mathrm{SH} / \sigma-\mathrm{CCl}$ and $\mathrm{SH} / \sigma-\mathrm{CH}$ couplings, i.e., the formation of IM2 is preferred over the formation of IM1, IM3 and IM4. Only the subsequent reaction steps of IM2 to afford PCTAs are investigated in pathway 1-4. The ring closure and intra-annular elimination of $\mathrm{Cl}$ require the highest potential barrier $(13.86 \mathrm{kcal} / \mathrm{mol})$ and is most endoergic $(18.24 \mathrm{kcal} / \mathrm{mol})$ and is regarded as the rate-determining step for pathway 1 . The ring closure and elimination of $\mathrm{H}$ steps occur separately, and the rate-determining step is the elimination of $\mathrm{H}$ for pathway 2, which has the highest potential barrier. Evidently, pathway 1 involves one less elementary steps compared to pathway 2. In addition, the rate determining step involved in pathway 1 has a lower potential barrier and is less endoergic $(\Delta E 13.86 \mathrm{kcal} / \mathrm{mol}, \Delta H 18.24 \mathrm{kcal} / \mathrm{mol})$ than that involved in pathway $2(\Delta E 33.22 \mathrm{kcal} / \mathrm{mol}, \Delta H 27.96 \mathrm{kcal} / \mathrm{mol})$. Therefore, pathway 1 is energetically preferred to pathway 2. Analogously, pathway 4 energetically preferred to pathway 3 . Comparing pathway 1 and pathway 4, pathway 4 involves two more elementary steps (smiles rearrangement) than pathway 
1. However, the rate-determining step involved in pathway 1 requires crossing a higher barrier and is more endothermic than pathway $4(\Delta E 12.52 \mathrm{kcal} / \mathrm{mol}, \Delta H 17.09 \mathrm{kcal} / \mathrm{mol})$. Therefore, pathway 1 and pathway 4 should be competitive. Thus, pathway 1 and pathway 4 are favored over the PCTA formation route, resulting in two dominant PCTA products (1,3,8-TCTA and 1,3,7-TCTA) from the coupling of R1 and R2.

It is evident from Figure $3 \mathrm{~b}$ that the formation of IM5 from $\mathrm{S} \bullet / \sigma-\mathrm{C} \bullet$ coupling $(-78.51 \mathrm{kcal} / \mathrm{mol})$ are much more exothermic than the formation of IM11 and IM12 from S• $/ \sigma-\mathrm{CCl}$ couplings $(-10.42 \mathrm{kcal} / \mathrm{mol}$

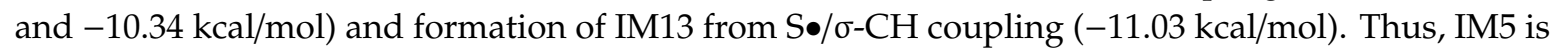
preferentially easier to form than IM11, IM12 and IM13. Only one intermediate IM5 was subject to further studies for the subsequent reaction to affording PCTAs in pathways 5-8. It can be seen that pathways 5-8 are similar to pathways $1-4$ and have one step less (sulfydryl-H abstraction) than pathways 1-4, respectively. Similar to cross-coupling of R1 and R2 in pathways 1-4, pathways 5 and 8 are competitive, and are the thermodynamically preferred PCTA formation route compared to pathways 6 and 7. 1,3,8-TCTA and 1,3,7-TCTA are also the main products from the coupling of R1 and DR.

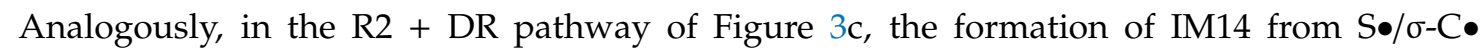
coupling $(-76.28 \mathrm{kcal} / \mathrm{mol})$ are much more exothermic than formation of IM15 from S॰ $/ \sigma-\mathrm{CCl}$ coupling $(9.53 \mathrm{kcal} / \mathrm{mol})$, formation of IM17 from SH$/ \sigma-\mathrm{CCl}$ coupling $(46.16 \mathrm{kcal} / \mathrm{mol})$ and formation of IM16 from SH/o-C coupling $(-37.79 \mathrm{kcal} / \mathrm{mol})$. Thus, IM14 is more easily to form than IM15, IM16 and IM17. Subsequently, after the initial sulfur-carbon coupling, IM14 evolves into 2,4,7,9-TeCTA though only one step: ring closure and elimination of $\mathrm{H}$, which is the rate-determining step for pathway 9 . It should be noted that the elimination of $\mathrm{H}$ step in pathways 2, 3, 6 and 7 is a separate reaction and causes the loss of the carbon- $\mathrm{H}$, while the ring closure and elimination of $\mathrm{H}$ step in pathway 9 is the concerted reaction and causes the loss of the sulfydryl- $\mathrm{H}$. In addition, the ring closure and elimination of $\mathrm{H}$ step in pathway 9 involves a much lower potential barrier $(4.39 \mathrm{kcal} / \mathrm{mol})$ and is less endoergic $(2.96 \mathrm{kcal} / \mathrm{mol})$ than the elimination of $\mathrm{H}$ step in pathways $2,3,6$ and 7 , which would proceed readily to yield 2,4,7,9-TeCTA at high temperature conditions.

In Figure $3 \mathrm{~d}$, the $\mathrm{S} \bullet / \sigma-\mathrm{C} \bullet$ coupling of DR + DR can directly afford 2,4,7,9-TeCTA and release much more heats $(-151.23 \mathrm{kcal} / \mathrm{mol})$ than the $\mathrm{S} \bullet / \sigma-\mathrm{CCl}$ couplings to form IM18. Moreover, the two coupling modes of R2 + R2 are found to be energetically not preferred by absorbing $62.46 \mathrm{kcal} / \mathrm{mol}$ heats and releasing $21.80 \mathrm{kcal} / \mathrm{mol}$ heats, respectively, which is not competitive with the carbon-carbon coupling with a large energy release of $113.98 \mathrm{kcal} / \mathrm{mol}$. Thus, the mainly R2 + R2 coupling product is PCDT rather than PCTA.

Comparison of the reaction pathways denoted in Figure 3a-d with previous research of R1 + R1 clearly shows that different radical couplings has a significant influence on the PCTA formation mechanism, especially on the sulfur-carbon coupling of CTPR [29]. The exothermicities of the sulfur-carbon coupling for R1 + R2, R1 + DR, R2 + DR, DR + DR, and R1 + R1 are 77.43, 78.51, $76.28,151.23$, and $11.64-11.99 \mathrm{kcal} / \mathrm{mol}$. In addition, the potential barrier of the rate determining step for R1 + R2, R1 + DR, R2 + DR, DR + DR, and R1 + R1 is 12.52-13.86, 12.52-13.86, 4.39, 0.00 and $12.52-15.25 \mathrm{kcal} / \mathrm{mol}$. Moreover, the number of elementary steps for R1 + R2, R1 + DR, R2 + DR, $\mathrm{DR}+\mathrm{DR}$, and R1 + R1 are 3-5, 2-4, 2, 1 and 3-5. Thus, the ranking of the PCTA formation potential is as follows: DR + DR $>$ R2 + DR $>$ R1 + DR $>$ R1 + R2 $>$ R1 + R1. It is also interesting to compare our date with the value with PCDD formation from coupling of oxygen-substituted radicals by Pan et al. at $\mathrm{BB} 1 \mathrm{~K} / 6-311+\mathrm{G}(3 \mathrm{df}, 2 \mathrm{p}) / / \mathrm{BB} 1 \mathrm{~K} / 6-311 \mathrm{G}(\mathrm{d}, \mathrm{p})$ level [36].The potential barriers of the rate determining step of the oxygen-carbon coupling for 2-chlorinated R1 + R2, R1 + DR, and R1 + R1 are all $34.5 \mathrm{kcal} / \mathrm{mol}$, which is higher than that of sulfur-carbon coupling for R1 + R2, R1 + DR and R1 + R1 in this study $(13.86 \mathrm{kcal} / \mathrm{mol})$ and our recent work [29]. In addition, the one-step reaction of oxygen-carbon coupling for 2-chlorinated R6 + R6 (-41.2 kcal/mol) in Pan's study is less exothermic than that of sulfur-carbon coupling for R6 + R6 in this study $(-151.23 \mathrm{kcal} / \mathrm{mol})$. The result indicates that the sulfureted dioxin compounds could be produced much more readily than the corresponding oxygenated dioxin systems. 


\subsection{Formation of PCDTs from $R 1, R 2$ and $D R$}

From Figure $4 \mathrm{a}$, the formation of IM19 from $\sigma-\mathrm{CCl} / \sigma-\mathrm{CCl}$ coupling and formation of IM22 from $\sigma-\mathrm{CH} / \sigma-\mathrm{CCl}$ coupling have high potential barriers $(47.84 \mathrm{kcal} / \mathrm{mol}$ and $44.96 \mathrm{kcal} / \mathrm{mol})$ and are strongly endothermic $(41.75 \mathrm{kcal} / \mathrm{mol}$ and $37.43 \mathrm{kcal} / \mathrm{mol})$, while the formation of IM20 from $\sigma-\mathrm{CH} / \sigma-\mathrm{C} \bullet$ coupling and formation of IM21 from $\sigma-\mathrm{CCl} / \sigma-\mathrm{C} \bullet$ coupling are barrierless and strong exothermic $(-47.28 \mathrm{kcal} / \mathrm{mol}$ and $-38.93 \mathrm{kcal} / \mathrm{mol}$ ). Thus, the formation of IM20 and IM21 are preferred over the formation of IM19 and IM22. Only the subsequent reaction steps of IM20 and IM21 to form PCDTs are investigated in pathway 11 and pathway 12. It can be seen that the ring closure step has the largest potential barrier and is the rate-determining step in each pathway. Notably, the rate-determining step involves in the formation of 2,6,8-TCDT in pathway12 requires a higher potential barrier $(18.22 \mathrm{kcal} / \mathrm{mol})$ than that involves in the formation of 2,4,6,8-TeCDT $(16.48 \mathrm{kcal} / \mathrm{mol})$ in pathway 11 . Moreover, the formation of 2,6,8-TCDT in pathway 12 are more endothermic $(5.37 \mathrm{kcal} / \mathrm{mol})$ than the formation of 2,4,6,8-TeCDT in pathway $11(3.45 \mathrm{kcal} / \mathrm{mol})$. Thus, pathway 11 is expected to compete against pathway 12 for PCDT formation, and 2,4,6,8-TeCDT is the main product from the coupling of R1 and R2.

In Figure $4 \mathrm{~b}$, the formation of IM27 and formation of IM30 have high potential barriers $(24.63 \mathrm{kcal} / \mathrm{mol}$ and $29.89 \mathrm{kcal} / \mathrm{mol})$ and are strongly endothermic $(19.25 \mathrm{kcal} / \mathrm{mol}$ and $26.90 \mathrm{kcal} / \mathrm{mol})$, while the formation of IM28 and formation of IM29 from R1 + DR are barrierless and strong exothermic $(-37.18 \mathrm{kcal} / \mathrm{mol}$ and $-47.51 \mathrm{kcal} / \mathrm{mol})$. Thus, the formation of IM28 and IM29 are overwhelmingly superior to the formation of IM27 and IM30. In addition, IM28 could not contribute to the formation of PCDT, because IM28 has no transferable $\mathrm{H}$ atom to form -SH, which needs to be eliminated in the PCDT formation. Thus, only the intermediate IM29 was further studied for the subsequent reaction to form $2,4,6,8-\mathrm{TeCDT}$. It can be seen that the potential barrier of the $\mathrm{H}$ shift step with water $(14.42 \mathrm{kcal} / \mathrm{mol})$ is higher than that of the direct $\mathrm{H}$ shift step without water $(-2.13 \mathrm{kcal} / \mathrm{mol})$, which indicates that water molecular has a negative catalytic role on the $\mathrm{H}$ shift and hinders the formation of PCDTs.

In Figure 4c, the formation of IM23 via R2 + DR releasing $111 \mathrm{kcal} / \mathrm{mol}$ heats in pathway 14 is shown. Analogously to the coupling of R1 + DR, the formation of IM32 has a high potential barrier and the formations of IM31 and IM33 hinder the formation of PCDTs. Thus, only the subsequent reactions of IM23 were studied in pathway 14, which covers only three elementary processes with one less step to form 2,4,6,8-TeCDT compared with pathway 11, 13 and 15. This means that pathway 14 is preferred over pathways 11-13. The $\sigma-\mathrm{C} \bullet / \sigma-\mathrm{C} \bullet$ coupling to form IM34 in Figure $4 \mathrm{~d}$ is barrierless and is more exothermic $(113.98 \mathrm{kcal} / \mathrm{mol})$ compared to the other two coupling modes to form IM35 and IM36. Following the similar elementary steps as R1 + R2 in Figure 4a, IM34 leads to the formation of 2,4,6,8-TeCDT.

Similarly, comparison of the reaction pathways presented in Figure $4 a-d$ with previous research of $\mathrm{R} 1+\mathrm{R} 1$ also indicate that different radical couplings can influence the PCDT formation [29]. The R1 + R2, $\mathrm{R} 1+\mathrm{DR}, \mathrm{R} 2+\mathrm{DR}$, and R2 + R2 couplings in this study are exothermic and barrierless (38.93-47.28, $47.51,111.44,113.98 \mathrm{kcal} / \mathrm{mol})$, while the R1 + R1 coupling is endothermic $(12.65-17.91 \mathrm{kcal} / \mathrm{mol})$ and with high potential barriers. In addition, the rate determining step of $\mathrm{R} 1+\mathrm{R} 2, \mathrm{R} 1+\mathrm{DR}$, R2 + DR, and R2 + R2 occurs in the ring closure step $(16.48 \mathrm{kcal} / \mathrm{mol})$ and are lower than that of R1 + R1 coupling, where the rate determining step occurs in the carbon-carbon coupling step and incurs high potential barriers $(22.09-24.46 \mathrm{kcal} / \mathrm{mol})$. Thus, the formation of PCDT from R1 + R2, R1 + DR, $\mathrm{R} 2+\mathrm{DR}$, and $\mathrm{R} 2+\mathrm{R} 2$ coupling can occur more efficiently than that from R1 + R1, and the ranking of the PCDT formation potential is as follows: $\mathrm{R} 2+\mathrm{DR}>\mathrm{R} 2+\mathrm{R} 2>\mathrm{R} 1+\mathrm{DR}>\mathrm{R} 1+\mathrm{R} 2>\mathrm{R} 1+\mathrm{R} 1$. Comparing with the values of rate determining step from the PCDF formation from coupling of oxygen-substituted radicals by Pan at BB1K/6-311+G(3df,2p)//BB1K/6-311G $(\mathrm{d}, \mathrm{p})$ level [36], the potential barriers for 2-chlorinated R1 + R2, R2 + DR and R2 + R2 and R1 + R1 are all $31.3 \mathrm{kcal} / \mathrm{mol}$, which is much higher than those for R1 + R2, R2 + DR and R2 + R2 (16.48 kcal $/ \mathrm{mol})$ in this study and that of $\mathrm{R} 1+\mathrm{R} 1(22.09 \mathrm{kcal} / \mathrm{mol})$ in our previous study [29]. The result also implies that PCDF formation from sulfur substituted self- and cross- radical-radical coupling reactions can occur more readily than PCDT 
formation from oxygen substituted coupling reactions, which may be explained by the differences induced by the different electronic properties of $\mathrm{S}$ and $\mathrm{O}$.

\subsection{Rate Constant Calculations}

The thermodynamic analysis of formation of R1 and R2 in Figure 1 shows that R1 is more stable and easier to form than R2. Comparision of the calculated CVT/SCT rate constants in these two steps also provided this conclusion. For example, at $1000 \mathrm{~K}$, the CVT/SCT rate constant for the reaction of 2,4-DCTP $+\mathrm{H} \rightarrow \mathrm{R} 1+\mathrm{H}_{2}$ via TS5 is $3.00 \times 10^{-12} \mathrm{~cm}^{3}$ molecule ${ }^{-1} \mathrm{~s}^{-1}$, which is larger than the value $1.32 \times 10^{-14} \mathrm{~cm}^{3}$ molecule ${ }^{-1} \mathrm{~s}^{-1}$ for the reaction of 2,4-DCTP $+\mathrm{H} \rightarrow \mathrm{R} 2+\mathrm{H}_{2}$ via TS6. Analogously, comparing of the calculated CVT/SCT rate constants for the formation of DR from R1 or R2 can reflect the conclusion in the thermodynamic analysis above that DR is more likely to form through $\mathrm{R} 2$ abstracted by $\mathrm{H}$ and $\mathrm{Cl}$ radicals, while for the $\mathrm{OH}$ radical abstracting reaction, DR is more likely to form through R1. For example, at $1000 \mathrm{~K}, \mathrm{CVT} / \mathrm{SCT}$ rate constants for the reaction of $\mathrm{R} 2+\mathrm{H} \rightarrow \mathrm{DR}+\mathrm{H}_{2}$ via TS8 is $9.46 \times 10^{-13} \mathrm{~cm}^{3}$ molecule ${ }^{-1} \mathrm{~s}^{-1}$, whereas the calculated value for the reaction of $\mathrm{R} 1+\mathrm{H} \rightarrow \mathrm{DR}+\mathrm{H}_{2}$ via TS7 is $1.16 \times 10^{-14} \mathrm{~cm}^{3}$ molecule $\mathrm{e}^{-1} \mathrm{~s}^{-1}$. In contrast, at $1000 \mathrm{~K}$, the CVT/SCT rate constants are $1.56 \times 10^{-13}$ and $8.07 \times 10^{-15} \mathrm{~cm}^{3}$ molecule ${ }^{-1} \mathrm{~s}^{-1}$ for reactions $\mathrm{R} 1+\mathrm{OH} \rightarrow \mathrm{DR}+\mathrm{H}_{2} \mathrm{O}$ via TS3 and $\mathrm{R} 2+\mathrm{OH} \rightarrow \mathrm{DR}+\mathrm{H}_{2} \mathrm{O}$ via TS4.

To confirm the route possibility of the PCTA/DT formation, it is important to compare the CVT/SCT rate constants of the rate-determining step in each pathway. For example, for the formation of PCTAs in pathway 1 and pathway 2, the calculated CVT/SCT rate constants is $3.58 \times 10^{8} \mathrm{~s}^{-1}$ for the reaction IM5 $\rightarrow 1,3,8$-TCTA $+\mathrm{Cl}$ via TS17 at $1000 \mathrm{~K}$, which is larger than the value $5.99 \times 10^{5} \mathrm{~s}^{-1}$ for the IM6 $\rightarrow$ 1,3,6,8-TeCTA + H via TS19 at $1000 \mathrm{~K}$. This reconfirms the finding of the thermodynamic analysis that pathways involved the elimination of $\mathrm{Cl}$ prefer over the pathways involved the elimination of $\mathrm{H}$ in the formation of PCTAs. For the formation of PCDTs in pathway 11 and pathway 12, at $1000 \mathrm{~K}$, the calculated CVT/SCT rate constants of IM23 $\rightarrow$ IM24 via TS32 in 2,4,6,8-TeCDT formation pathways is $7.24 \times 10^{7} \mathrm{~s}^{-1}$, which is larger than the value $7.07 \times 10^{7} \mathrm{~s}^{-1}$ of IM25 $\rightarrow$ IM26 via TS38 in 2,6,8-TCDT formation pathways. This is consistent with the thermodynamic analysis: formation of 2,4,6,8-TeCDT is easier to facilitate than the formation of 2,6,8-TCDT.

\section{Materials and Methods}

Quantum chemistry calculations were carried out in the framework of density functional theory (DFT) using the Gaussian 09 program package [45]. The geometries optimizations for reactants, intermediates, transition states and products were conducted using the hybrid meta functional, MPWB1K, which gives uniformly excellent performance for thermochemistry, thermochemical kinetics, hydrogen bonding, and weak interactions, with the standard $6-31+G(d, p)$ basis set [46]. The vibrational frequencies were also calculated at the MPWB1K/6-31+G(d,p) level in order to determine the nature of the stationary points, the zero-point energy ( $\mathrm{ZPE})$, and the thermal contributions to the free energy of activation. Intrinsic reaction coordinate (IRC) calculations and the minimum energy paths (MEPs) were performed to verify that each transition state is connected to two desired minima [47]. To obtain more reliable potential barriers and reaction heats, the single-point energy calculations were refined using a more flexible basis set, $6-311+G(3 d f, 2 p)$, based on the optimized geometries. All the energies quoted and discussed in this paper include ZPE corrections. The kinetic constant calculations were performed using the POLYRATE 9.7 program [48]. The rate constants were calculated using canonical variational transition-state theory (CVT), and quantum tunneling corrections were considered by the small curvature tunneling (SCT) method [41-44]. The rate constants of each reaction were calculated over a wide temperature range (600-1200 K), which covers the possible formation temperature of PCTA/DTs in municipal waste incinerators [41-44]. 


\section{Conclusions}

In this study, mechanisms were used to investigate the homogenous gas-phase formation of PCTA/DTs from self/cross-coupling of 2,4-dichlorothiophenoxy radical (R1), 2-sulfydryl-3,5-dichlorophenyl radical (R2) and 3,5-dichlorothiophenoxyl diradical (DR). The formation reactions of $\mathrm{R} 1, \mathrm{R} 2$ and $\mathrm{DR}$ abstracted by $\mathrm{OH}, \mathrm{H}, \mathrm{Cl}$ radicals were also studied. Several energetically preferred routes for PCTA/DTs formation were proposed. The formation potential for PCTA/DT formation from different coupling were sorted and compared with our previous study. Four specific conclusions can be drawn.

(1) Besides the chlorothiophenoxy radical (R1), the sulfydryl-substituted phenyl radical (R2) and the thiophenoxyl diradical (DR) also contribute to the formation of PCTA/DTs, and the PCTA/DT formation pathways proposed in this study are proved to be both thermodynamically and kinetically feasible.

(2) The main PCTA products from self- and cross-coupling of R1, R2 and DR are 1,3,7-TCTA, 1,3,8-TCTA and 2,4,7,9-TeCTA. The $\mathrm{S} \bullet / \sigma-\mathrm{C} \bullet$ condensation with both thiophenolic sulfur in one radical and ortho carbon in the other radical bonded to single electron is the most efficient sulfur-carbon coupling mode, and the order of the PCTA formation potential is as follows: DR + DR $>$ R2 + DR $>$ R1 $+\mathrm{DR}>\mathrm{R} 1+\mathrm{R} 2>\mathrm{R} 1+\mathrm{R} 1$.

(3) The main PCDT products from self- and cross-coupling of R1, R2 and DR are 2,4,6,8-TeCDT. The $\sigma-\mathrm{C} \bullet / \sigma-\mathrm{C} \bullet$ coupling with both ortho carbon in the two radicals bonded to single electron is the energetically favored carbon-carbon coupling mode, and the ranking of the PCDT formation potential is: $\mathrm{R} 2+\mathrm{DR}>\mathrm{R} 2+\mathrm{R} 2>\mathrm{R} 1+\mathrm{DR}>\mathrm{R} 1+\mathrm{R} 2>\mathrm{R} 1+\mathrm{R} 1$.

(4) The PCTA/DTs produced from R1, R2 and DR can occur much more readily than PCDD/DFs formation from corresponding oxygen substituted radicals.

Supplementary Materials: Supplementary Materials can be found at http://www.mdpi.com/1422-0067/20/ $11 / 2623 / \mathrm{s} 1$. Figure S1. PCTA/DTs formation routes embedded with the reaction heats $\Delta H$ (in $\mathrm{kcal} / \mathrm{mol}$ ) from self-couplings of $\mathrm{R} 2$ and DR. $\Delta H$ is calculated at $0 \mathrm{~K}$. Table S1. The potential barriers $\Delta E$ (in $\mathrm{kcal} / \mathrm{mol}$ ) and reaction heats $\Delta H$ (in $\mathrm{kcal} / \mathrm{mol}$ ) of several typical reactions in the formation of PCTA/DTs at MPWB1K/6-311+G(3df,2p)//MPWB1K/6-31+G(d,p) and BB1K/6-311+G(3df,2p) //BB1K/6-311G(d,p) levels. Table S2. Imaginary frequencies (in $\mathrm{cm}^{-1}$ ), zero point energies (ZPE, in a.u.) and total energies (in a.u.) for the transition states involved in the formation of PCTA/DTs from R1, R2 and DR. Table S3. CVT/SCT rate constants for the formation of PCTA/DTs from R1, R2 and DR over the temperature range of 600-1200 K (units are s and cm $^{-1}$ molecule $\mathrm{e}^{-1} \mathrm{~s}^{-1}$ for unimolecular and bimolecular reactions, respectively). Table S4. Cartesian coordinates for the transition states involved in the formation of PCTA/DTs from R1, R2 and DR. Table S5. Cartesian coordinates for the reactants, intermediates and products involved in the formation of PCTA/DTs from R1, R2 and DR.

Author Contributions: H.W. designed and performed the mechanism calculations, then wrote the manuscript; H.W., C.Z. and S.Z. performed the kinetic calculation. H.W., Y.S., F.X. and Q.Z. all analyzed the data in the manuscript.

Funding: This research was funded by NSFC (National Natural Science Foundation of China, project Nos. 21677089, 21607089), Shenzhen Science and Technology Research and Development Funds (project Nos. JCYJ20160510165106371), FRFSDU (The Fundamental Research Funds of Shandong University, project Nos. 2016WLJH51, 2017JC033), the China Postdoctoral Science Foundation funded project (project Nos. 2017M612277, 2017T100493), SKLECRA (The open foundation of state key laboratory of environmental criteria and risk assessment, Chinese research academy of environmental sciences No. 2016OFP09), Applied Basic Research Program of Qingdao (No. 17-1-1-15-jch).

Acknowledgments: The authors thank Donald G. Truhlar for providing the POLYRATE 9.7 program.

Conflicts of Interest: The authors declare no conflict of interest. 


\section{Abbreviations}

$\begin{array}{ll}\text { PCDTs } & \begin{array}{l}\text { polychlorinated dibenzothiophenes } \\ \text { polychlorinated thianthrenes }\end{array} \\ \text { PCDDs } & \begin{array}{l}\text { polychlorinated dibenzo-p-dioxins } \\ \text { polychlorinated dibenzofurans } \\ \text { PCDFs }\end{array} \\ \text { R1 } & \text { 2,4-dichlorothiophenoxy radical } \\ \text { R2 } & \text { 3,5-dichlorothiophenoxyl diradical } \\ \text { DR } & \text { 1,3,8-trichlorothianthrene } \\ \text { 1,3,8-TCTA } & \text { 1,3,6,8-tetrachlorothianthrene } \\ \text { 1,3,6,8-TeCTA } & \text { 1,3,7,9-tetrachlorothianthrene } \\ \text { 1,3,7,9-TeCTA } & \text { 1,3,7-trichlorothianthrene } \\ \text { 1,3,7-TCTA } & \text { 2,4,7,9-tetrachlorothianthrene } \\ \text { 2,4,7,9-TeCTA } & \text { 2,4,6,8-tetrachlorodibenzothiophene } \\ \text { 2,4,6,8-TeCDT } & \text { 2,6,8-trichlorodibenzothiophene } \\ \text { 2,6,8-TeCDT } & \text { density functional theory } \\ \text { DFT } & \text { transition state theory } \\ \text { TST } & \text { intrinsic reaction coordinate } \\ \text { IRC } & \text { zero-point energy } \\ \text { ZPE } & \text { minimum energy paths } \\ \text { MEPs } & \text { canonical variational transition-state theory } \\ \text { CVT } & \text { small curvature tunneling } \\ \text { SCT } & \end{array}$

\section{References}

1. Sinkkonen, S.; Kolehmainen, E.; Paasivirta, J.; Koistinen, J.; Lahtipera, M.; Lammi, R. Identification and level estimation of chlorinated neutral aromatic sulfur compounds and their alkylated derivatives in pulp mill effluents and sediments. Chemosphere 1994, 28, 2049-2066. [CrossRef]

2. Sinkkonen, S. New Types of Persistent Halogenated Compounds; Springer: Berlin, Germany, 2000; Volume 3, pp. $289-314$.

3. Kopponen, P.; Krenlampi, S.; Sinkkonen, S. Sulphur analogues of polychlorinated dioxins, furans and diphenylethers as inducers of aryl hydrocarbon hydroxylase. Organohalogen Compd. 1993, 13, $229-232$.

4. Nakai, S.; Kishita, S.; Nomura, Y.; Hosomi, M. Polychlorinated dibenzothiophenes in Japanese environmental samples and their photodegradability and dioxin-like endocrine-disruption potential. Chemosphere 2007, 67, 1852-1857. [CrossRef]

5. Weber, R.; Hagenmaier, H.; Schrenk, D. Elimination kinetics and toxicity of 2,3,7,8-tetrachlorothiantheren, a thio analogue of 2, 3, 7, 8-TCDD. Chemosphere 1998, 36, 2635-2641. [CrossRef]

6. Buser, H.R.; Rappe, C. Determination of polychlorodibenzothiophenes, the sulfur analogs of polychlorodibenzofurans, using various gas chromatographic/mass spectrometric techniques. Anal. Chem. 1991, 63, 1210-1217. [CrossRef]

7. Sinkkonen, S.; Vattulainen, A.; Aittola, J.-P.; Paasivirta, J.; Tarhanen, J.; Lahtiperä, M. Metal reclamation produces sulphur analogues of toxic dioxins and furans. Chemosphere 1994, 28, 1279-1288. [CrossRef]

8. Rappe, C. Sources of exposure, environmental concentrations and exposure assessment of PCDDs and PCDFs. Chemosphere 1993, 27, 211-225. [CrossRef]

9. Sinkkonen, S.; Kolehmainen, E.; Koistinen, J.; Lahtiperä, M. High-resolution gas chromatographic-mass spectrometric determination of neutral chlorinated aromatic sulphur compounds in stack gas samples. J. Chromatogr. A 1993, 641, 309-317. [CrossRef]

10. Pruell, R.; Taplin, B.; McGovern, D.; McKinney, R.; Norton, S. Organic contaminant distributions in sediments, polychaetes (Nereis virens) and American lobster (Homarus americanus) from a laboratory food chain experiment. Mar. Environ Res. 2000, 49, 19-36. [CrossRef]

11. Pruell, R.; Rubinstein, N.; Taplin, B.; LiVolsi, J.; Bowen, R. Accumulation of polychlorinated organic contaminants from sediment by three benthic marine species. Arch. Environ. Contam. Toxicol. 1993, 24, 290-297. [CrossRef]

12. Huntley, S.; Wenning, R.; Paustenbach, D.; Wong, A.; Luksemburg, W. Potential sources of polychlorinated dibenzothiophenes in the Passaic River, New Jersey. Chemosphere 1994, 29, 257-272. [CrossRef] 
13. Klasmeier, J.; Matthies, M.; Macleod, M.; Fenner, K.; Scheringer, M.; Stroebe, M.; Le Gall, A.C.; Mckone, T.; Van De Meent, D.; Wania, F. Application of multimedia models for screening assessment of long-range transport potential and overall persistence. Environ. Sci. Technol. 2006, 40, 53-60. [CrossRef]

14. Sinkkonen, S.; Paasivirta, J.; Lahtiperä, M. Chlorinated and methylated dibenzothiophenes in sediment samples from a river contaminated by organochlorine wastes. J. Soils Sediments 2001, 1, 9-14. [CrossRef]

15. Buser, H. Identification and sources of dioxin-like compounds: I. Polychlorodibenzothiophenes and polychlorothianthrenes, the sulfur-analogues of the polychlorodibenzofurans and polychlorodibenzodioxins. Chemosphere 1992, 25, 45-48. [CrossRef]

16. Sinkkonen, S.; Paasivirta, J.; Koistinen, J.; Tarhanen, J. Tetra-and pentachlorodibenzothiophenes are formed in waste combustion. Chemosphere 1991, 23, 583-587. [CrossRef]

17. Sato, S.; Matsumura, A.; Urushigawa, Y.; Metwally, M.; Al-Muzaini, S. Structural analysis of weathered oil from Kuwait's environment. Environ. Int. 1998, 24, 77-87. [CrossRef]

18. Atlas, R. Fate of oil from two major oil spills: Role of microbial degradation in removing oil from the Amoco Cadiz and IXTOC I spills. Environ. Int. 1981, 5, 33-38. [CrossRef]

19. Cai, Z.W.; Giblin, D.E.; Ramanujam, V.S.; Gross, M.L.; Cristini, A. Mass-profile monitoring in trace analysis: Identification of polychlorodibenzothiophenes in crab tissues collected from the Newark/Raritan Bay system. Environ. Sci. Technol. 1994, 28, 1535-1538. [CrossRef] [PubMed]

20. Parette, R.; Pearson, W.N. 2,4,6,8-Tetrachlorodibenzothiophene in the Newark Bay Estuary: The likely source and reaction pathways. Chemosphere 2014, 111, 157-163. [CrossRef] [PubMed]

21. Dar, T.; Altarawneh, M.; Dlugogorski, B. Theoretical study in the dimerisation of 2-chlrothiophenol/2-chlorothiophenoxy: Precursors to PCDT/TA. Organohalogen Compd. 2012, 74, 657-660.

22. Dar, T.; Altarawneh, M.; Dlugogorski, B.Z. Quantum chemical study on formation of PCDT/TA from 2-chlorothiophenol precursor. Environ. Sci. Technol. 2013, 47, 11040-11047. [CrossRef] [PubMed]

23. Navarro, R.; Bierbrauer, K.; Mijangos, C.; Goiti, E.; Reinecke, H. Modification of poly (vinyl chloride) with new aromatic thiol compounds. Synthesis and characterization. Polym. Degrad. Stab. 2008, 93, 585-591. [CrossRef]

24. Dar, T.; Shah, K.; Moghtaderi, B.; Page, A.J. Formation of persistent organic pollutants from 2, 4, 5-trichlorothiophenol combustion: a density functional theory investigation. J. Mol. Model. 2016, 22, 128. [CrossRef] [PubMed]

25. Evans, C.S.; Dellinger, B. Mechanisms of dioxin formation from the high-temperature pyrolysis of 2-chlorophenol. Environ. Sci. Technol. 2003, 37, 1325-1330. [CrossRef]

26. Evans, C.S.; Dellinger, B. Mechanisms of dioxin formation from the high-temperature oxidation of 2-chlorophenol. Environ. Sci. Technol. 2005, 39, 122-127. [CrossRef]

27. Zhang, Q.Z.; Li, S.Q.; Qu, X.H.; Shi, X.Y.; Wang, W.X. A quantum mechanical study on the formation of PCDD/Fs from 2-chlorophenol as precursor. Environ. Sci. Technol. 2008, 42, 7301-7308. [CrossRef] [PubMed]

28. Qu, X.H.; Wang, H.; Zhang, Q.Z.; Shi, X.Y.; Xu, F.; Wang, W.X. Mechanistic and kinetic studies on the homogeneous gas-phase formation of PCDD/Fs from 2,4,5-trichlorophenol. Environ. Sci. Technol. 2009, 43, 4068-4075. [CrossRef] [PubMed]

29. Xu, F.; Shi, X.L.; Li, Y.F.; Zhang, Q.Z. Mechanistic and kinetic studies on the homogeneous gas-phase formation of PCTA/DTs from 2,4-dichlorothiophenol and 2,4,6-trichlorothiophenol. Int. J. Mol. Sci. 2015, 16, 20449-20467. [CrossRef]

30. Yu,X.Q.; Chang,J.M.; Liu, X.; Pan, W.X.; Zhang, A.Q. Theoretical study on the formation mechanism of polychlorinated dibenzothiophenes/thianthrenes from 2-chlorothiophenol molecules. J. Environ. Sci. 2018, 66, 318-327. [CrossRef]

31. Briois, C.; Visez, N.; Baillet, C.; Sawerysyn, J.-P. Experimental study on the thermal oxidation of 2-chlorophenol in air over the temperature range $450-900{ }^{\circ} \mathrm{C}$. Chemosphere 2006, 62, 1806-1816. [CrossRef] [PubMed]

32. Kaiser, R.; Parker, D.; Zhang, F.; Landera, A.; Kislov, V.; Mebel, A. PAH formation under single collision conditions: reaction of phenyl radical and 1,3-butadiene to form 1,4-dihydronaphthalene. J. Phys. Chem. A 2012, 116, 4248-4258. [CrossRef]

33. Shukla, B.; Susa, A.; Miyoshi, A.; Koshi, M. Role of phenyl radicals in the growth of polycyclic aromatic hydrocarbons. J. Phys. Chem. A 2008, 112, 2362-2369. [CrossRef]

34. Bonnichon, F.; Richard, C.; Grabner, G. Formation of an $\alpha$-ketocarbene by photolysis of aqueous 2-bromophenol. Chem. Commun. 2001, 1, 73-74. [CrossRef]

35. Lomnicki, S.; Truong, H.; Dellinger, B. Mechanisms of product formation from the pyrolytic thermal degradation of catechol. Chemosphere 2008, 73, 629-633. [CrossRef] [PubMed] 
36. Pan, W.X.; Zhang, D.J.; Han, Z.; Zhan, J.H.; Liu, C.B. New insight into the formation mechanism of PCDD/Fs from 2-chlorophenol precursor. Environ. Sci. Technol. 2013, 47, 8489-8498. [CrossRef]

37. Sinkkonen, S. Sources and environmental fate of PCDTs. Toxicol Environ. Chem. 1998, 66, 105-112. [CrossRef]

38. Czerwiński, J. Pathways of polychlorinated dibenzothiophenes (PCDTs) in the environment. Arch. Environ. Prot. 2008, 34, 169-181.

39. Xu, F.; Shi, X.L.; Zhang, Q.Z.; Wang, W.X. Formation of chlorotriophenoxy radicals from complete series reactions of chlorotriophenols with $\mathrm{H}$ and $\mathrm{OH}$ radicals. Int. J. Mol. Sci. 2015, 16, 18714-18731. [CrossRef]

40. Zhang, Q.Z.; Qu, X.H.; Wang, W.X. Mechanism of OH-initiated atmospheric photooxidation of dichlorvos: A quantum mechanical study. Environ. Sci. Technol. 2007, 41, 6109-6116. [CrossRef]

41. Baldridge, K.K.; Gordon, M.S.; Steckler, R.; Truhlar, D.G. Ab initio reaction paths and direct dynamics calculations. J. Phys. Chem. 1989, 93, 5107-5119. [CrossRef]

42. Gonzalez-Lafont, A.; Truong, T.N.; Truhlar, D.G. Interpolated variational transition-state theory: Practical methods for estimating variational transition-state properties and tunneling contributions to chemical reaction rates from electronic structure calculations. J. Chem. Phys. 1991, 95, 8875-8894. [CrossRef]

43. Garrett, B.C.; Truhlar, D.G. Generalized transition state theory. Classical mechanical theory and applications to collinear reactions of hydrogen molecules. J. Phys. Chem. 1979, 83, 1052-1079. [CrossRef]

44. Fernandez-Ramos, A.; Ellingson, B.A.; Garret, B.C.; Truhlar, D.G. Variational transition state theory with multidimensional tunneling. In Reviews in Computational Chemistry; Lipkowitz, K.B., Cundari, T.R., Eds.; Wiley-VCH: Hoboken, NJ, USA, 2007.

45. Frisch, M.J.; Trucks, G.W.; Schlegel, H.B.; Scuseria, G.E.; Robb, M.A.; Cheeseman, J.R.; Scalmani, G.; Barone, V.; Mennucci, B.; Petersson, G.A.; et al. Gaussian 09, Revision A.02; Gaussian, Inc.: Wallingford, CT, USA, 2009.

46. Zhao, Y.; Truhlar, D.G. Hybrid meta density functional theory methods for thermochemistry, thermochemical kinetics, and noncovalent interactions: The MPW1B95 and MPWB1K models and comparative assessments for hydrogen bonding and van der Waals interactions. J. Phys. Chem. A 2004, 108, 6908-6918. [CrossRef]

47. Fukui, K. The path of chemical reactions-the IRC approach. Acc. Chem. Res. 1981, 14, 363-368. [CrossRef]

48. Corchado, J.C.; Chuang, Y.Y.; Fast, P.L.; Villa, J.; Hu, W.P.; Liu, Y.P.; Lynch, G.C.; Nguyen, K.A.; Jackels, C.F.; Melissas, V.S.; et al. POLYRATE Version 9.7; University of Minnesota: Minneapolis, MN, USA, 2007.

(C) 2019 by the authors. Licensee MDPI, Basel, Switzerland. This article is an open access article distributed under the terms and conditions of the Creative Commons Attribution (CC BY) license (http://creativecommons.org/licenses/by/4.0/). 